\title{
Color-Coding of Microchip RT-PCR Test System for SARS-CoV-2 Detection
}

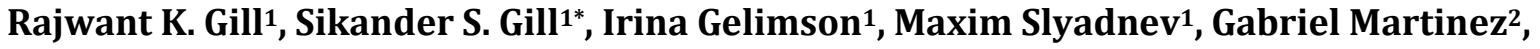 \\ Michelle Gaines ${ }^{2}$, Ryan Nunley², Timea Majoros ${ }^{2}$ \\ ${ }^{1}$ Lumex Instruments Canada, Mission, BC, Canada \\ ${ }^{2}$ 1CARE Medical Diagnostics, Benicia, CA, USA \\ Email: *sikander.gill@lumexinstruments.com
}

How to cite this paper: Gill, R.K., Gill, S.S., Gelimson, I., Slyadnev, M., Martinez, G., Gaines, M., Nunley, R. and Majoros, T. (2021) Color-Coding of Microchip RT-PCR Test System for SARS-CoV-2 Detection. Journal of Biosciences and Medicines, 9, 94-119.

https://doi.org/10.4236/jbm.2021.95010

Received: April 16, 2021

Accepted: May 24, 2021

Published: May 27, 2021

Copyright $\odot 2021$ by author(s) and Scientific Research Publishing Inc. This work is licensed under the Creative Commons Attribution International License (CC BY 4.0).

http://creativecommons.org/licenses/by/4.0/

\begin{abstract}
An RT-PCR based microchip test system for the detection of SARS-CoV-2 offers pre-loaded and lyophilized reagents in the microchip. However, the 30and 48-microwell formats of the microchip being miniaturized and performing $1.2 \mu \mathrm{l}$ reaction, seek visual attention during sample addition. Therefore, adding colorants as color indicator in the lyophilized matrix in the microchips or adding to sample or master mix can impart not only user-friendliness to the task of liquid handling but also precision, and color-codes for easy identification of multiple kits in the layout of the microchip without compromising PCR data quality. A panel of colorants was screened for their background intensity, spectral inertness towards detection channels of AriaDNA $^{\mathrm{TM}}$ analyzer, interference with the reporter dyes (FAM, Cy5 and ROX), and visibility of optimal concentration in the microwell. The concentration of the colorant displaying insignificant impact on the quality of the amplification (Ct, fluorescence, and sensitivity) in comparison to no-colorant control was chosen for inclusion in the test kit. Tartrazine, Acid Red, Brilliant Blue and FAST Green colorants lyophilized with the reagents in the SARS-CoV-2 microchips were found to be stable and suitable. Storage of microchips with Fast Green colorant was tested at $40^{\circ} \mathrm{C}, 22^{\circ} \mathrm{C}, 4^{\circ} \mathrm{C}$, and $-20^{\circ} \mathrm{C}$ for 70 days and was found to be suitable and compatible with different master mixes available as liquid or lyophilized. Additionally, the microchips pre-loaded with lyophilized reagents in the presence and absence of two colorants Tartrazine and Fast Green were validated with clinical samples of SARS-COV-2. No significant impact of these colorants both intra- and inter-microchips was observed on the $\mathrm{Ct}$ and intensity of amplification for the tested samples in comparison to no-colorant control. The data suggested that the tested colorants can be used to color the sample, or the master mix or PCR mix for user-friendly liquid handling in empty microchips. For the microchip with
\end{abstract}


pre-loaded and lyophilized reagents, the colorant can be added to lyophilized mixture for precision liquid handling and color-coding of lyophilized kits in the microchips. The manufacturing quality of the lyophilized microchips can also improve with colorant loaded reagent mix.

\section{Keywords}

SARS-CoV-2, Colorants, Microchip, PCR, 2-Plex

\section{Introduction}

A microchip based realtime RT-PCR test system consisting of a 1-plex disposable microchip for the detection of SARS-CoV-2 has gone through the validation of this detection assay with clinical samples [1]. This microchip consists of 30 microwells, each of which can accommodate a miniature TaqMan chemistry-based reaction of $1.2 \mu \mathrm{l}$. The microchip is preloaded with lyophilized US-CDC recommended $\mathrm{N} 1$ and N2 primers and probes for detecting the nucleocapsid (N) gene of this virus, along with HsRPP30 (Hs) as a human specimen control involving 1-step qRT-PCR reactions. Recently, we have developed a 2-plex format of the microchip for SARS-CoV-2 detection in which the N1 gene target has been paired with the Hs target in each microwell of the microchip raising the throughput from 7 samples in 1-plex test kit to 27 samples in addition to the controls performing 45 cycles in 32 minutes. Another 2-plex test system with increased throughput of 45 samples in 32 min has higher density of microwells (48-microwell, columns $8 \times$ rows 6 ). Apart from SARS-CoV-2 detection, the microchip based realtime PCR test systems are involved in detection of other targets including phytopathogens, GMOs, pashmina fibers, meat identifiers, and others as 1-plex or 2-plex test systems [2] [3] [4] [5] [6].

These next generation test systems are technically optimized for imparting sensitivity, specificity, reproducibility, cost-effectiveness, and rapidity in results [2]-[7]. Most of these advantages are attributed to the miniaturized reaction volume, high heat transfer efficiency offered by the metal plate with etched microwells providing high surface area to volume ratio, low reagent consumption, surface dominant properties, and cost-effective product design [7]. The reduced thermal mass of microchips allows for extremely fast temperature ramping requiring PCR protocols established plate-based reactors to be adjusted to the microchips [8]-[16]. Therefore, the attributes of this technology are expected to meet the current requirements and demands of existing detection assays, giving fast results in under 30 minutes [17].

To ease reagent addition to the microcwells and ensuring surface inertness to the PCR process, the passivation of exposed metal surfaces offers hydrophilicity to the microwells that attracts the liquid reagents to the microwells. This feature of the microchip offers user-friendliness in liquid handling and retention of the reagent mix in the microwells. However, the PCR master mixes being colorless 
are difficult to visualize in the microwells. This challenge gets aggravated when microchips are manufactured to be offered as ready-to-use test systems with PCR reagents lyophilized in the microwells. Additional challenge is posed by further miniaturization and higher density of wells in the 48-microwell format. These features of the microchip test systems demand more attention for careful pipetting into the reagent pellet loaded microwells. However, by including PCR compatible colorant(s) as standalone reagent for adding into the PCR reagent mix for running PCR in empty microchips or including the colorant into lyophilized pellet of the reagents in ready-to-run microchips, can prove highly user-friendly (Figure 1(a)). Therefore, in view of the practical considerations involved in adopting the colorants in this technology for routine laboratory use, and for precision of quality control in the manufacturing process, precision in running assays, and as color-code identifier, the validation task was attempted.

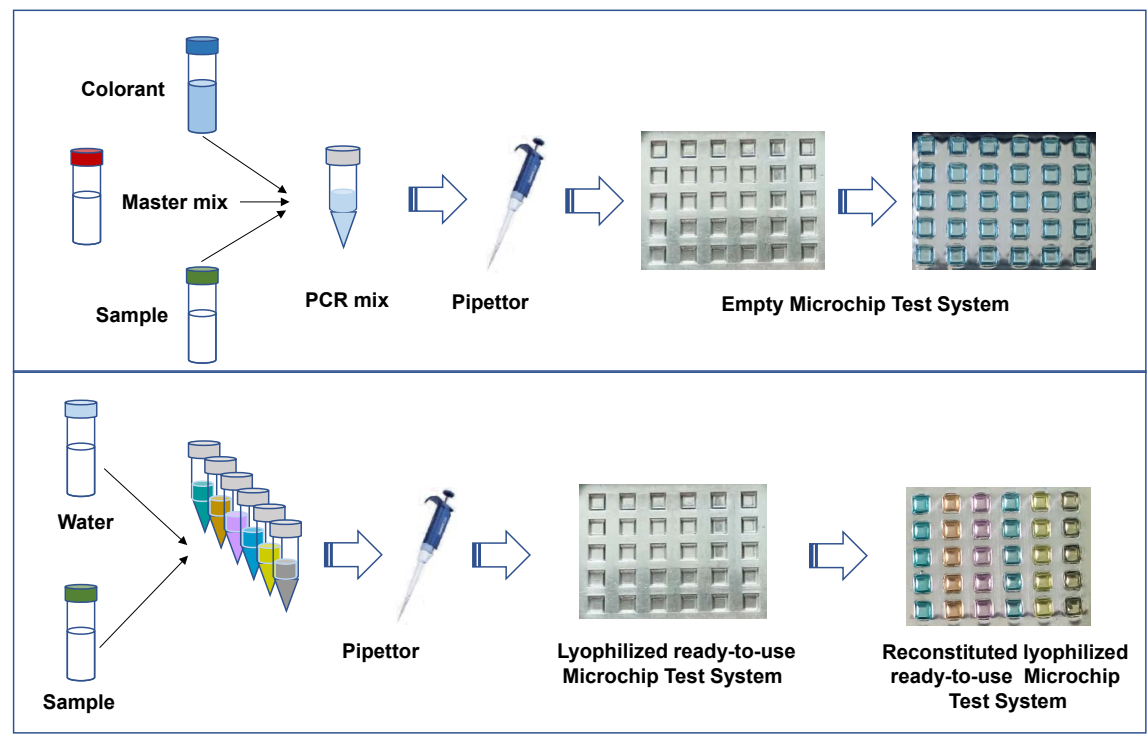

(a)

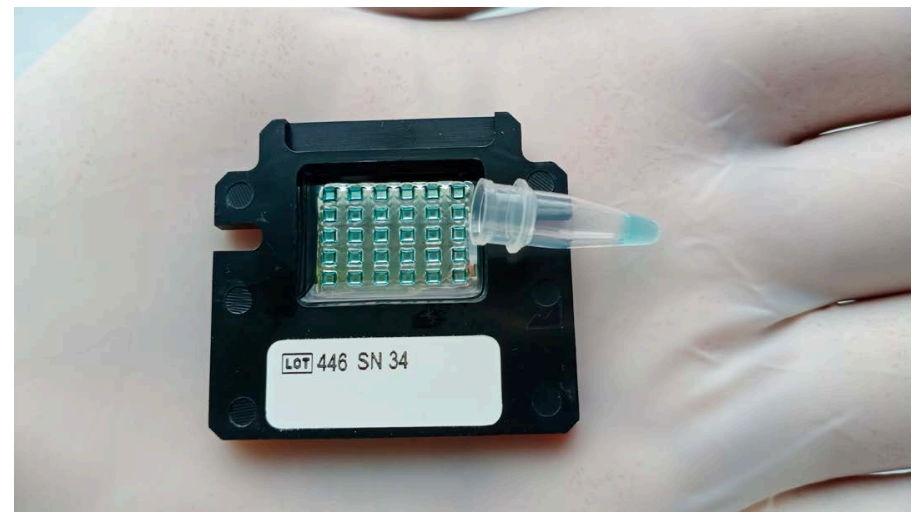

(b)

Figure 1. (a) The application of colorants as precision and color-codes in qPCR assays. (b) A microchip on palm filled with $1.2 \mu \mathrm{l}$ of Fast Green colorant displaying visibility of microwells loaded with colorant-PCR mix in contrast to metal base of the microchip. A PCR tube with $20 \mu \mathrm{l}$ of the same colorant-PCR mix is presented for comparison. 


\section{Materials \& Methods}

Reagents: The reagents used in these studies were prepared as follows:

1) PCR reagents: The CDC emergency authorization employs $2019-\mathrm{nCoV}$ CDC EUA Kit (Cat \# 10006770) that includes primers \& probes supplied by Integrated DNA Technology Inc, USA (http://www.idtdna.com). Following the $\mathrm{CDC}$ protocol, the primer-probe set to detect $\mathrm{N} 1$ region of the $\mathrm{N}$ gene of SARS-CoV-2 virus, and the second primer-probe set to detect Hs, a house keeping gene of human subject as a sample control. UltraPlex ${ }^{\mathrm{TM}} 1$-Step ToughMix ${ }^{\circledR}$, a $4 \mathrm{X}$ concentrated master mix for 1-step qRT-PCR containing dATP, dCTP, dGTP, dTTP, magnesium, qScript XLT reverse transcriptase, RNase inhibitor protein and AccuStart II hot-start Taq DNA polymerase, catalogue \# 95166-01K procured from Quanta Bio, MA, USA (http://www.quantabio.com) was utilized as the TaqMan Taq polymerase enzyme premix for real-time PCR on the microchip. Lyo NZYSupreme One-step RT-qPCR Probe and Lyo NZYSpeedy one-step RT-qPCR Probe master mixes available in lyophilized form were obtained from NZY Tech, Lisboa, Portugal, https://www.nzytech.com.

2) Preparation of viral RNA: As a positive control in all experiments, $\mathrm{Ar}$ mored RNA that includes the viral sequences for the N1 RNA of SARS-CoV-2, 1 $\times 10^{11}$ copies $/ \mathrm{ml}$, Cat \# 52030, and Hs Armored RNA Cat \# 52031, $1 \times 10^{11}$ copies $/ \mathrm{mL}$, used as an alternative template to the human housekeeping gene (Hs) was obtained from Asuragen, Inc., Austin, TX, USA http://www2.asuragen.com/.

3) Preparation of colorants: Individual solution of five different colorants Brilliant Blue FCF (cat \# 80717), Sunset Yellow FCF (cat \# 68775), Fast Green FCF (cat \# 68724), Acid Red 33 (cat \# 59573), and Tartrazine (cat \# 03322) purchased from Millipore Sigma Aldrich, USA were prepared by dissolving $1 \mathrm{mg}$ of the colorant dry powder in a known quantity of DNAse/RNAse free water to generate an intense tinge of the color. A series of 2 -fold dilutions of each colorant solution was prepared to an extent that $1 \mu \mathrm{l}$ of the last dilution in the series added to $9 \mu \mathrm{l}$ of water could give visually an end point of the colorant tinge. The colorant preparations were carried in amber color tubes to avoid exposure to direct light. The stock preps of colorants were stored in $-20^{\circ} \mathrm{C}$ freezer while working solution was stored in a fridge at $4^{\circ} \mathrm{C}$ in a black box. A set of serial dilutions of each colorant were tested for the inhibition of the PCR amplification or any other spectral impact on the AriaDNA ${ }^{\mathrm{TM}}$ channels to determine appropriately acceptable dilution. Each experiment was performed with 5 replicates (n $=5$ ). Based on the concentration of the acceptable dilution, a working stock of each colorant solution was prepared for further studies (Table 1).

4) Preparation of disposable pre-filled microchips: Empty microchips with 30 microwells ( 6 columns $\times 5$ rows) and 48 microwells ( 8 columns $\times 6$ rows) were manufactured from aluminum sheets, and stainless-steel, respectively by metal stamping technology and coated with surface modifiers [1]. This coating imparts hydrophilicity to the microwells of $1.2 \mu \mathrm{l}$ capacity and hydrophobicity to the upper surface of the microchips. The empty microchips were then filled with 
Table 1. Optimal working concentration of colorants.

\begin{tabular}{cccc}
\hline$\#$ & Colorant & Weight $(\mathrm{mg})$ & Nuclease-free Water $(\mathrm{ml})$ \\
\hline $\mathbf{1}$ & Brilliant Blue FCF & 1.0 & 6.0 \\
$\mathbf{2}$ & Sunset Yellow FCF & 1.0 & 7.2 \\
$\mathbf{3}$ & Fast Green FCF & 1.0 & 13.333 \\
$\mathbf{4}$ & Acid Red 33 & 1.0 & 10.0 \\
$\mathbf{5}$ & Tartrazine & 1.0 & 1.0 \\
\hline
\end{tabular}

a $1.2 \mu \mathrm{l}$ solution of primers and probes of $\mathrm{N} 1$, and $\mathrm{Hs}$ along with stabilizing agents and the colorant using a OT2 robotic workstation from Opentrons, USA (http://www.opentrons.com) in a predefined layout (Figure 2(a), Figure 2(b)). The relative size of the microchips and the microwells is demonstrated with colorant filled microchip on palm in comparison to $20 \mu \mathrm{l}$ filled in a PCR tube (Figure 1(b)). The prefilled microchips were then lyophilized by Lumex Instruments, Canada using a SJIA-10N Lyophilizer of Ningbo Shuangjia Instrument Co., Ltd (http://www.shuangiayiqi.com) and each microchip was individually packaged in a package with desiccant [1].

Microchip-based 1-step RT-PCR: Real-time RT-PCR was performed on the microchip-based PCR analyzer AriaDNA ${ }^{\mathrm{TM}}$ (http://www.lumexinstruments.com) using manufacturer's software to control the instrument and obtain PCR results [1]. Following the standard procedure, before the addition of the reaction mix in the microchip, $620 \mu \mathrm{l}$ of silicone oil layer was added for the purpose of overlaying the reaction mix to contain evaporation of the reagents during processing and thermocycling. The mix of sample and master mix was quickly followed by submerged liquid handling under the oil layer. The mix of the sample and master mix for the RT-PCR assays was prepared as UltraPlex ${ }^{\mathrm{TM}}$ 1-Step ToughMix ${ }^{\mathbb{B}}$ : viral RNA: ddH2O in the volumetric ratio of 1:1:2. To prepare Negative Template Control (NTC), viral RNA was replaced with $\mathrm{ddH}_{2} \mathrm{O}$ or RNA Storage Solution. To prepare Positive Template Control (PTC), viral RNA was replaced with in vitro transcribed SARS-Cov-2 RNA $\left(1 \times 10^{5}\right.$ copies/ul $)$ mixed with Hs RNA ( 1 $\times 10^{5}$ copies/ul).

For testing the effect of colorants in empty microchips, $1 \mu \mathrm{l}$ of the colorant was added to $9 \mu \mathrm{l}$ of the reaction mix [primers, probe(s) and master mix] making a total of $10 \mu \mathrm{l}$ for distribution as $1.2 \mu \mathrm{l}$ in the microwells. In the preloaded or ready-to-use microchips containing lyophilized assays in the microchips, $1 \mu \mathrm{l}$ of the colorant was added to $9 \mu \mathrm{l}$ of the sample and master mix making a total of 10 $\mu$ l. Each microchip was loaded with the prepared reaction samples alongside two NTCs and one PTC. Each sample and control was loaded into the microwells containing SARS-CoV-2 targets (N1) and human sample control (Hs) pri-

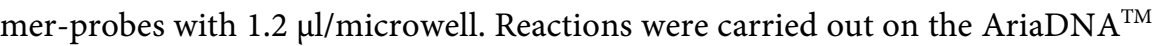
PCR analyzer as one-step PCR cycling and run as 5 replicates $(n=5)$, if not stated otherwise. 


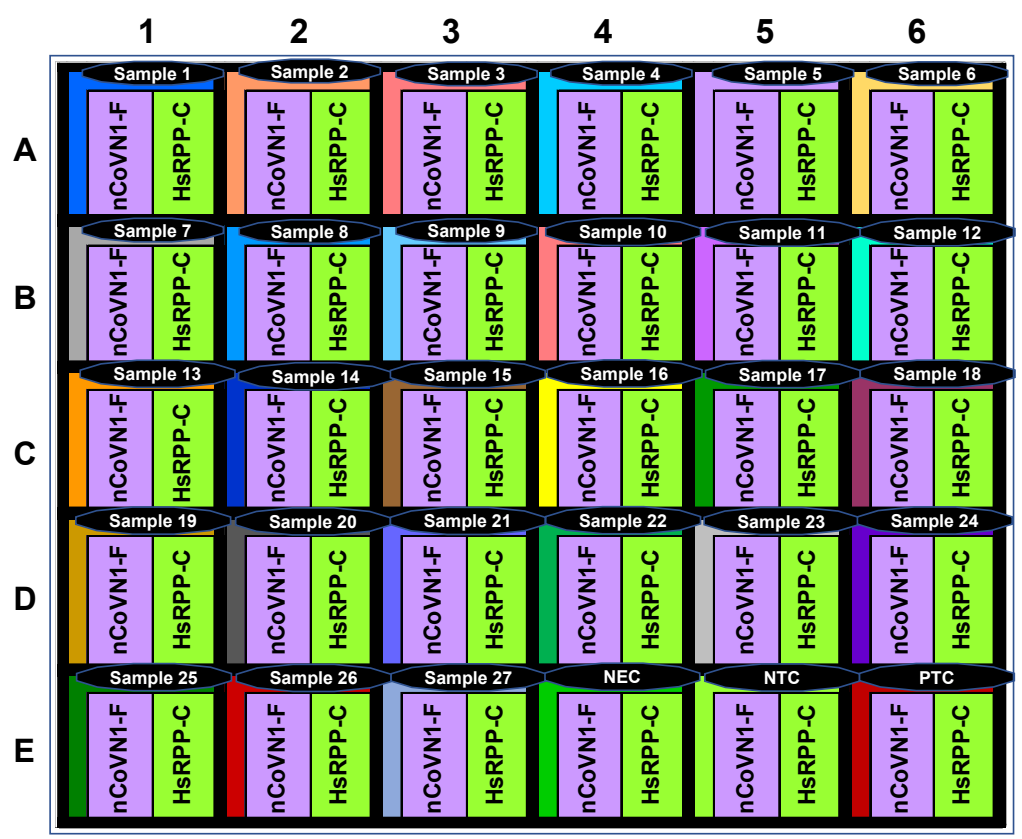

(a)

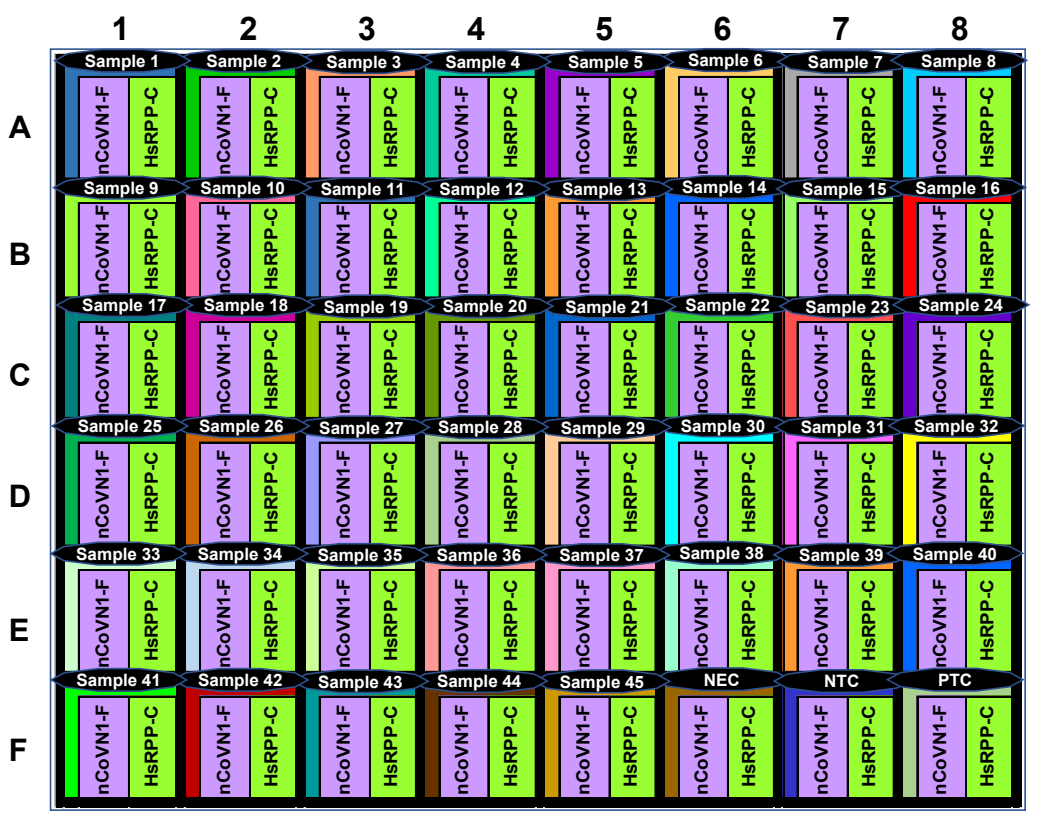

(b)

Figure 2. Microchip RT-PCR Covid-19 Detection Kit- with 2-plex (a) 30-microwell format with layout of 27 samples, NEC, NTC, and PTC. (b) 48-microwell format with layout of 45 samples, NEC, NTC, and PTC.

Slow or fast thermal settings were applied, including a reverse transcription step at $50^{\circ} \mathrm{C}$ for $300 \mathrm{~s}$, followed by a denaturing step at $95^{\circ} \mathrm{C}$ for $120 \mathrm{~s}$ and 45 cycles of $95^{\circ} \mathrm{C}$ for $1 \mathrm{~s}$ followed by extension and signal recording at $55^{\circ} \mathrm{C}$ for $20 \mathrm{~s}$. The $\mathrm{Ct}$ values were determined as a second derivative maximum (SDM) once fluorescence passed an auto-set SDM threshold. The SDM serves as an automated alternative but manually tweakable threshold setting and confers flexibil- 
ity of the software on the instrument. SDM value is reported when an amplitude of the fluorescent signal and an amplitude of its first derivative are both above the pre-set thresholds. Those threshold values can be adjusted within AriaD$\mathrm{NA}^{\mathrm{TM}}$ software and were set at 150 and 30 arbitrary units, respectively.

Screening of colorants for PCR compatibility: $1 \mu \mathrm{l}$ of the test dilution of each colorant was added to $9 \mu \mathrm{l}$ of master mix for distributing $1.2 \mu \mathrm{l}$ of this colored mix into wells of the microchip. A comparative control was also performed in the same microchip without the colorant. Each experiment was run with 5 replicates $(\mathrm{n}=5)$ :

1) Checking inhibitory effect of colorants on PCR: To determine any dose dependent impact of the colorant on PCR, an experiment was designed to test an intense solution of Brilliant Blue colorant $(1 \mathrm{mg} / 0.3 \mathrm{ml})$ and its last two 2-fold serial dilutions $(1 \mathrm{mg} / 3 \mathrm{ml}$, and $1 \mathrm{mg} / 6 \mathrm{ml})$ on amplification of N1-FAM and Hs-Cy5 targets. The Ct values and fluorescence intensity (IU) of the PCR were monitored. Similar concentrations $(1 \mathrm{mg} / 0.36 \mathrm{ml}, 1 \mathrm{mg} / 3.6 \mathrm{ml}, 1 \mathrm{mg} / 7.2 \mathrm{ml})$ of Sunset Yellow were tested.

With the purpose of minimising the dose dependent inhibitory effect of the colorant displayed by the test dilutions of Brilliant Blue and Sunset Yellow, the last three serial dilutions (2-fold) of the remaining colorants (Fast Green, 1 $\mathrm{mg} / 3.33 \mathrm{ml} 1 \mathrm{mg} / 6.66 \mathrm{ml} 1 \mathrm{mg} / 13.33 \mathrm{ml}$; Acid Red 33, $1 \mathrm{mg} / 2.5 \mathrm{ml} 1 \mathrm{mg} / 5 \mathrm{ml} 1$ $\mathrm{mg} / 10 \mathrm{ml}$, and Tartrazine $1 \mathrm{mg} / 0.25 \mathrm{ml} 1 \mathrm{mg} / 0.5 \mathrm{ml} 1 \mathrm{mg} / 1 \mathrm{ml}$ ) offering visibly apparent color in the PCR reaction were tested. Depending upon the acceptability of the results in comparison to the no colorant control, the least visible concentration or higher concentration of each colorant was selected as working concentration of the colorant leading to the preparation of stock working solutions of the screened colorants (Table 1).

2) Determining background intensity in empty microchips: The background intensity of $1 \mu \mathrm{l}$ of the working concentration of each colorant in $10 \mu \mathrm{l}$ of water, in $10 \mu$ l of UltraPlex ${ }^{\mathrm{TM}} 1$-Step ToughMix ${ }^{\circledR}$, in10 $\mu$ l of PCR mix containing UltraPlex $^{\mathrm{TM}} 1$-Step ToughMix ${ }^{\circledR}$ and primer probes of N1-FAM and Hs-Cy5 was determined in empty microchips. The standard thermal PCR profile was run for 45 cycles to determine any impact of temperature in comparison to the no-colorant control. The PCR mix contained UltraPlex ${ }^{\mathrm{TM}} 1$-Step ToughMix ${ }^{\circledR}$, and primers and probes of both N1-FAM and Hs-Cy5/Hs-ROX along with N1-RNA and Hs-RNA.

3) Determining spectral interference of colorants in empty microchips: The interference of the working solutions of the test colorants with channel-1 and channel- 2 of AriaDNA ${ }^{\mathrm{TM}}$ analyzer was determined by running PCR using 1 $\mu \mathrm{l}$ of the colorant as a sample instead of N1- or Hs-RNA. Similarly, the interference of the colorant with FAM and Cy5 reporter dyes was studied by adding colorant in the presence of N1-RNA determining cross channel interference in the absence of Hs-RNA and vice versa.

4) Determining spectral interference of colorants in lyophilized microchips: The inhibition effect of the colorants was investigated by adding working 
concentration of the colorant $\left(1 \mu \mathrm{l}\right.$ in $10 \mu \mathrm{l}$ RT-PCR mix containing UltraPlex ${ }^{\mathrm{TM}}$ 1-Step ToughMix $\left.{ }^{\circledR}\right)$ in the 2-plex Microchip RT-PCR Covid-19 Detection kit preloaded with N1-FAM, and Hs-Cy5 reporter dyes. Any change in the $\mathrm{Ct}(\Delta \mathrm{Ct})$ and change in fluorescence intensity $(\Delta \mathrm{IU})$ of with/without (w/o) colorants were determined.

5) Comparison of sensitivity and LOD of PCR w/o colorant: Effect of the working concentrations of all the 5 test colorants on sensitivity and limit of detection (LOD) of the RT-PCR was performed using low number of copies (1 copy/ $\mu \mathrm{l}$ ) of N1-RNA in the presence of higher number of copies of Hs-RNA in comparison to no-colorant control. Comparative $\mathrm{Ct}$ values were determined along with fluorescence intensities.

6) Compatibility with master mixes and stability of colorants in lyophilized microchips: The microchips were lyophilized with primers and probes of both N1-FAM and Hs-Cy5 in 2-plex format. In the lyophilized mixture, no colorant control, and working concentration of Fast Green colorant was included in column \# 1 - 3, and $4-6$, respectively.

The stability studies of the lyophilized microchips were carried by storing one set of 13 microchips at each of the storage temperature: $-20^{\circ} \mathrm{C}, 4^{\circ} \mathrm{C}, 22^{\circ} \mathrm{C}$, and $40^{\circ} \mathrm{C}$ over a duration of test schedule. The test schedule was drawn for testing one microchip from each of the storage temperature on 0 -day, $7^{\text {th }}$-day, followed by every 21 day till the $13^{\text {th }}$ microchip was tested. Following the test schedule, the RT-PCR was performed with the lyophilized microchips thus prepared using PCR mix prepared with UltraPlex ${ }^{\mathrm{TM}} 1$-Step ToughMix ${ }^{\circledR}$ in column \# 1 and 4 , the Lyo NZYSupreme One-step RT-qPCR Probe Master Mix in column \# 2 and 5, and Lyo NZYSpeedy one-step RT-qPCR Probe Master Mix in column \# 3 and 6 along with 125 copies the N1-RNA and 1250 copies/ $\mu$ lof Hs-RNA. The Ct values and fluorescence intensity were monitored to determine deviation in comparison to no-colorant control.

7) Test of colorant loaded Microchip with clinical samples of Covid-19: One lot of microchips was prepared and lyophilized with primers and probes of N1-FAM and Hs-Cy5 in which columns $1-2$ did not include any colorant, while column $3-4$ and column 5 - 6 included working concentration of Tartrazine and Fast Green colorants. Another lot of microchips were similarly prepared and lyophilized replacing Hs-Cy5 with Hs-ROX reporter dye. Positive extraction control (PEC) and negative extraction control (NEC), and some patient samples were testes in these microchips to determine the comparative effect of these colorants with no-colorant control. The PEC and NEC were tested as duplicates to determine intra-microchip and inter-microchip comparison. The PEC and NEC samples were tested in two replicates $(\mathrm{n}=2)$ while other samples were run as single replicate $(n=1)$.

\section{Results and Discussion}

Screening of colorants for PCR compatibility and inertness: To determine 
dose dependent impact of the colorant on PCR, an intense solution of Brilliant Blue colorant and its two last serial dilutions was tested by adding $1 \mu \mathrm{l}$ from each of these test 3 dilutions to PCR reaction with N1-FAM and Hs-Cy5 targets. The intense dose of the colorant completely inhibited the PCR while the last two dilutions had insignificant dose-dependent effect on the amplification intensity (IU) in comparison to no-colorant control. However, the $\mathrm{Ct}$ values of the N1-FAM target by the intense dose were delayed to Ct 32.1 while both the mild dilutions of the colorant did not impact the Ct relative to no-colorant control. The amplification of Hs-Cy5 target was completely inhibited by the intense dose while both the mild dilutions did not affect both the $\mathrm{Ct}$ and IU (Table 2, Figure 3(a), Figure 3(b)).

A similar behaviour of the intense and mild doses of the Sunset Yellow colorant was displayed by the amplification Ct value of Hs-Cy5 target by completely inhibiting the amplification by the intense dose and no impact by the mild doses on $\mathrm{Ct}$ values and amplification intensity. However, the intense dose of the colorant displayed complete inhibition of amplification of the N1-FAM target while

Table 2. Impact of colorants on PCR of N1 and Hs targets of SARS Cov-2.

\begin{tabular}{|c|c|c|c|c|c|c|c|c|c|}
\hline \multirow{2}{*}{ Colorant } & \multirow{2}{*}{ Channel- } & \multicolumn{2}{|c|}{$1^{\text {st }}$ Dilution } & \multicolumn{2}{|c|}{$2^{\text {nd }}$ Dilution } & \multicolumn{2}{|c|}{$3^{\text {rd }}$ Dilution } & \multicolumn{2}{|c|}{ No-Colorant } \\
\hline & & $\mathrm{Ct}$ & IU & $\mathrm{Ct}$ & IU & $\mathrm{Ct}$ & IU & $\mathrm{Ct}$ & IU \\
\hline & & $1 \mathrm{mg}$ & $0.3 \mathrm{ml}$ & $1 \mathrm{~m}$ & $/ 3 \mathrm{ml}$ & $1 \mathrm{~m}$ & $/ 6 \mathrm{ml}$ & Co & trol \\
\hline \multirow[t]{3}{*}{ Brilliant Blue FCF } & N1 & 32.1 & 800 & 27.1 & 5700 & 27.1 & 5500 & 27.1 & 5500 \\
\hline & Hs & $-\mathrm{Ve}$ & $-\mathrm{Ve}$ & 27.7 & 2400 & 27.7 & 2600 & 27.6 & 2800 \\
\hline & & $1 \mathrm{mg} /$ & $.36 \mathrm{ml}$ & $1 \mathrm{mg}$ & $3.6 \mathrm{ml}$ & $1 \mathrm{mg}$ & $7.2 \mathrm{ml}$ & Co & trol \\
\hline \multirow[t]{3}{*}{ Sunset Yellow FCF } & N1 & $-\mathrm{Ve}$ & 110 & 27.0 & 1800 & 27.0 & 3600 & 27.0 & 6000 \\
\hline & Hs & 27.7 & 2600 & 27.7 & 3200 & 27.7 & 3200 & 27.6 & 3200 \\
\hline & & \multicolumn{2}{|c|}{$1 \mathrm{mg} / 3.33 \mathrm{ml}$} & \multicolumn{2}{|c|}{$1 \mathrm{mg} / 6.66 \mathrm{ml}$} & \multicolumn{2}{|c|}{$1 \mathrm{mg} / 13.33 \mathrm{ml}$} & \multicolumn{2}{|c|}{ Control } \\
\hline \multirow[t]{3}{*}{ Fast Green FCF } & N1 & 26.8 & 4800 & 26.9 & 5400 & 26.6 & 5200 & 26.8 & 5400 \\
\hline & Hs & 26.8 & 1600 & 27.5 & 2200 & 26.9 & 2300 & 27.2 & 2700 \\
\hline & & \multicolumn{2}{|c|}{$1 \mathrm{mg} / 2.5 \mathrm{ml}$} & \multicolumn{2}{|c|}{$1 \mathrm{mg} / 5 \mathrm{ml}$} & \multicolumn{2}{|c|}{$1 \mathrm{mg} / 10 \mathrm{ml}$} & \multicolumn{2}{|c|}{ Control } \\
\hline \multirow[t]{3}{*}{ Acid Red } & N1 & 26.8 & 3800 & 26.8 & 4500 & 26.8 & 4800 & 26.8 & 5200 \\
\hline & Hs & 27.5 & 2300 & 27.5 & 2600 & 27.4 & 2800 & 27.3 & 2800 \\
\hline & & \multicolumn{2}{|c|}{$1 \mathrm{mg} / 0.25 \mathrm{ml}$} & \multicolumn{2}{|c|}{$1 \mathrm{mg} / 0.5 \mathrm{ml}$} & \multicolumn{2}{|c|}{$1 \mathrm{mg} / 1 \mathrm{ml}$} & \multicolumn{2}{|c|}{ Control } \\
\hline \multirow[t]{2}{*}{ Tartrazine } & N1 & 29.0 & 4100 & 28.7 & 4500 & 28.7 & 5000 & 28.7 & 5500 \\
\hline & Hs & 28.2 & 3100 & 28.1 & 3100 & 28.1 & 3100 & 28.2 & 3100 \\
\hline Turquoise & N1 & 28.9 & 4500 & & & & & 28.5 & 5500 \\
\hline Fast Green + Sunset Yellow (3:1) & Hs & 28.6 & 2700 & & & & & 28.3 & 3100 \\
\hline Purple & N1 & 28.9 & 4200 & & & & & 28.5 & 5500 \\
\hline Acid Red + Brilliant Blue $(3: 1)$ & Hs & 28.2 & 2800 & & & & & 28.3 & 3100 \\
\hline Light Green & N1 & 28.9 & 5000 & & & & & 28.5 & 5500 \\
\hline Fast Green + Tartrazine (3:1) & Hs & 28.5 & 2800 & & & & & 28.3 & 3100 \\
\hline
\end{tabular}




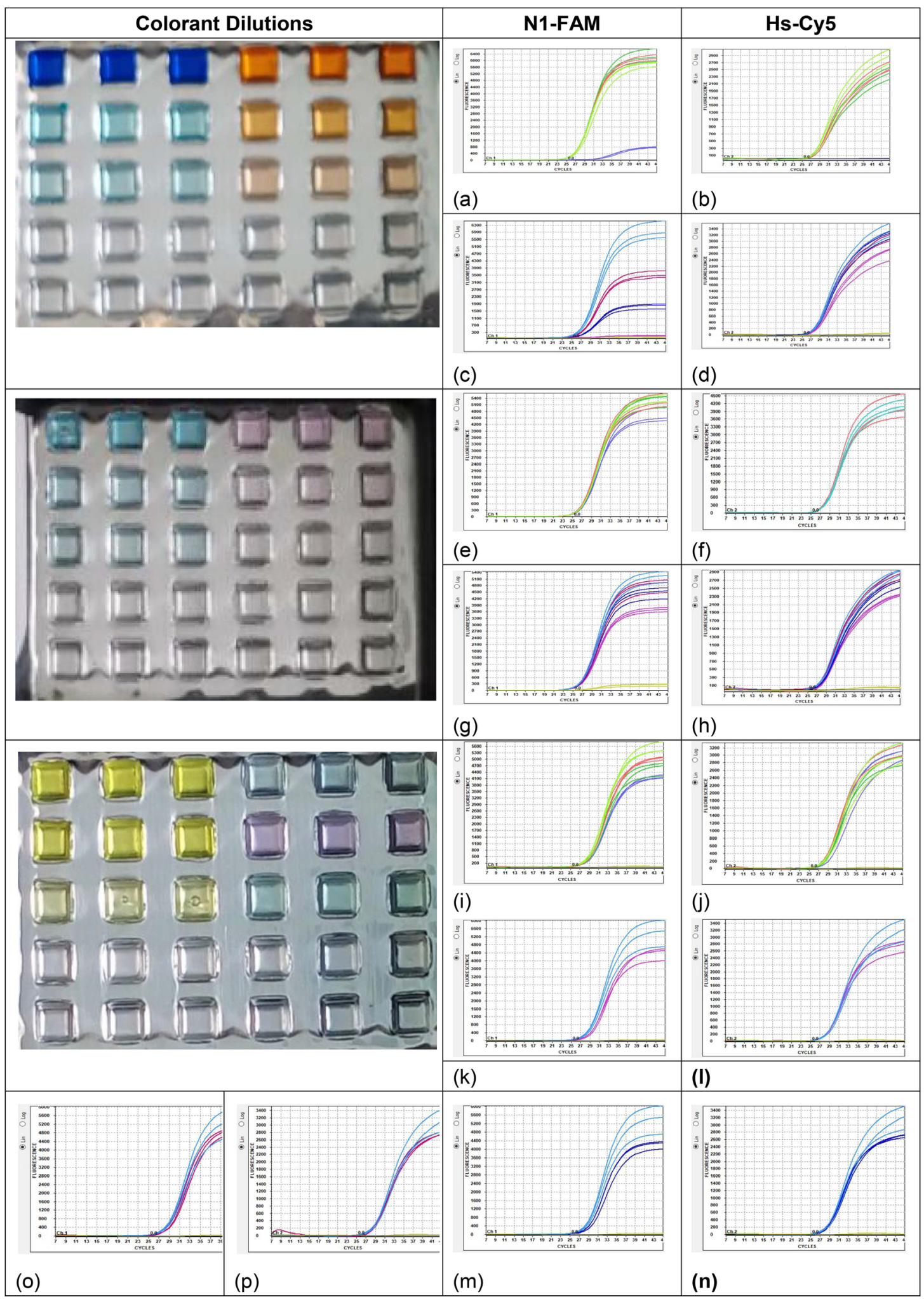

Figure 3. Screening of colorant dilutions on channel-1 (FAM reporting dye), and channel-2 (Cy5 reporting dye). (a \& b) Brilliant Blue $1 \mathrm{mg} / 0.3 \mathrm{ml}, 1 \mathrm{mg} / 3 \mathrm{ml}$, and $1 \mathrm{mg} / 6 \mathrm{ml}$, (c \& d) Sunset Yellow $1 \mathrm{mg} / 0.36 \mathrm{ml}, 1$ $\mathrm{mg} / 3.6 \mathrm{ml}, 1 \mathrm{mg} / 7.2 \mathrm{ml}$, (e \& f) Fast Green $1 \mathrm{mg} / 3.33 \mathrm{ml}, 1 \mathrm{mg} / 6.66 \mathrm{ml}, 1 \mathrm{mg} / 13.33 \mathrm{ml}$, (g \& h) Acid Red 1 $\mathrm{mg} / 2.5 \mathrm{ml}, 1 \mathrm{mg} / 5 \mathrm{ml}, 1 \mathrm{mg} / 10 \mathrm{ml}$, (i \& j) Tartrazine $1 \mathrm{mg} / 0.25 \mathrm{ml}, 1 \mathrm{mg} / 0.5 \mathrm{ml}, 1 \mathrm{mg} / 1 \mathrm{ml}$, and derivative colorants (k \& l) Turquoise, (m \& n) Purple, (o \& p) Light Green. 
a dose-dependent reduction of intensity in comparison to no-colorant control but without affecting $\mathrm{Ct}$ values was observed. The Hs-Cy5, however, had consistent $\mathrm{Ct}$ values among the tested concentrations with insignificant reduction of amplification intensities even by the intense colorant (Table 2, Figure 3(c), Figure 3(d)).

With the purpose of minimising the inhibitory effect of the colorant, the last three 2-fold serial dilutions of the remaining colorants offering visible tinge of the colorant ( $1 \mu \mathrm{l}$ in $10 \mu \mathrm{l}$ of PCR reaction) were tested. All the three tested concentrations displayed consistent $\mathrm{Ct}$ values and amplification intensities comparable to no-colorant control. Additional colorant shades were also derived by mixing the working concentrations of the test colorants in specific ratios (volume: volume, Table 3). The results indicated the impact of the derived colorant shade was an average of the impact of the mixing colorants (Table 2, Figures $3(\mathrm{~m})-(\mathrm{p})$ The insignificant $\Delta \mathrm{Ct}$ and $\Delta \mathrm{IU}$ of w/o colorant supported further studies on the use of these colorants in the microchip (Table 2, Figures 3(e)-(p), Figure 4(a), Figure 4(b)).

This data is supported by the commercially available VisiBlue ${ }^{\mathrm{TM}}$, and the Precision Blue colorant solutions of undisclosed chemical name(s), considered inert reagent colorants for realtime PCR applications where the end amplification intensity level is slightly reduced by these colorants comparative to no-colorant control when added to a PCR reaction mix. This reduction, however, is reported to vary with the master mix used in the reaction

(https://www.tataa.com/wp-content/uploads/2012/10/TATAA-Manual_VisiBlue -1.3.pdf, https://www.bio-rad.com/webroot/web/pdf/lsr/literature/Bulletin_6090.pdf).

Determining background intensity of colorants: The background intensity of the working concentrations of the test colorants in water, and in UltraPlex ${ }^{\mathrm{TM}}$ 1-Step ToughMix ${ }^{\circledR}$ were observed close to that of the no-colorant control on both the channels of AriaDNA ${ }^{\mathrm{TM}}$ analyzer except Acid Red 33 colorant. The latter had about 2-fold higher background intensity than that of the no-colorant control. However, in the presence of primer and probes of N1-FAM, Fast Green, Brilliant Blue, Tartrazine and Acid Red 33 colorant had background intensity about 0.9 to 1.2 -fold that of the no-colorant control (Figure 5(a)). In the case of

Table 3. Derivative colorants from working concentrations of the tested colorants.

\begin{tabular}{ccccc}
\hline Derivative colorants & & Test colorants & Ratio \\
\hline Sea green & Brilliant Blue & Tartrazine & - & $1: 1$ \\
Parrot Green & Brilliant Blue & Sunset Yellow & - & $1: 1$ \\
Purple & Brilliant Blue & Acid Red 33 & - & $1: 4$ \\
Dark Brown & Brilliant Blue & Tartrazine & Acid Red 33 & $1: 1: 4$ \\
Green & Fast Green & Tartrazine & - & $1: 4$ \\
Sunset Yellow & Acid Red 33 & Tartrazine & - & $1: 4$ \\
\hline
\end{tabular}


Hs-Cy5, the background intensity of Tartrazine, and Sunset Yellow colorants in water, in UltraPlex ${ }^{\mathrm{TM}} 1$-Step ToughMix ${ }^{\circledR}$, in the PCR mix containing UltraPlex ${ }^{\mathrm{TM}}$

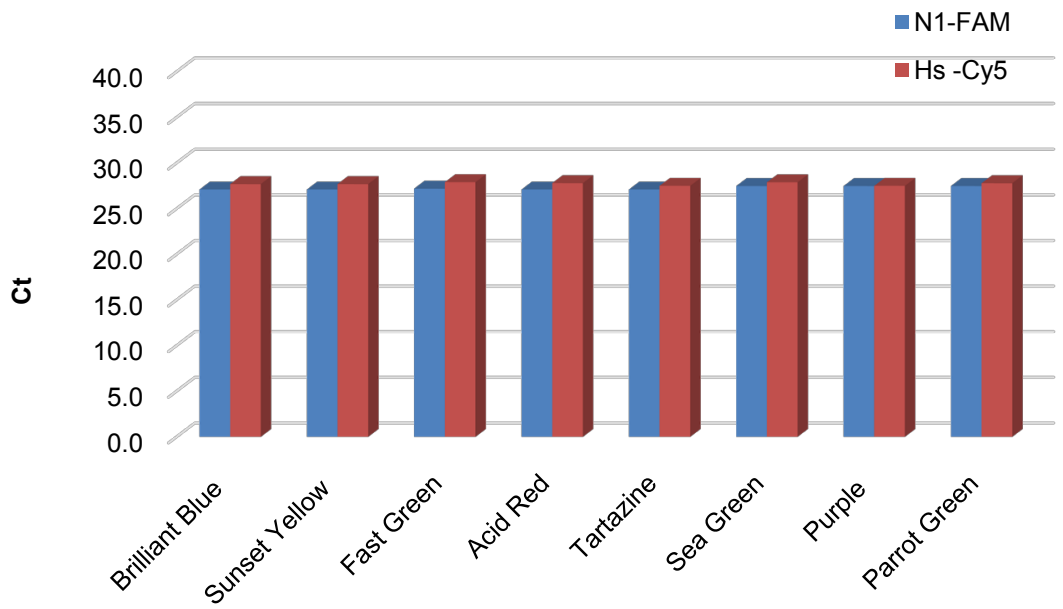

(a)

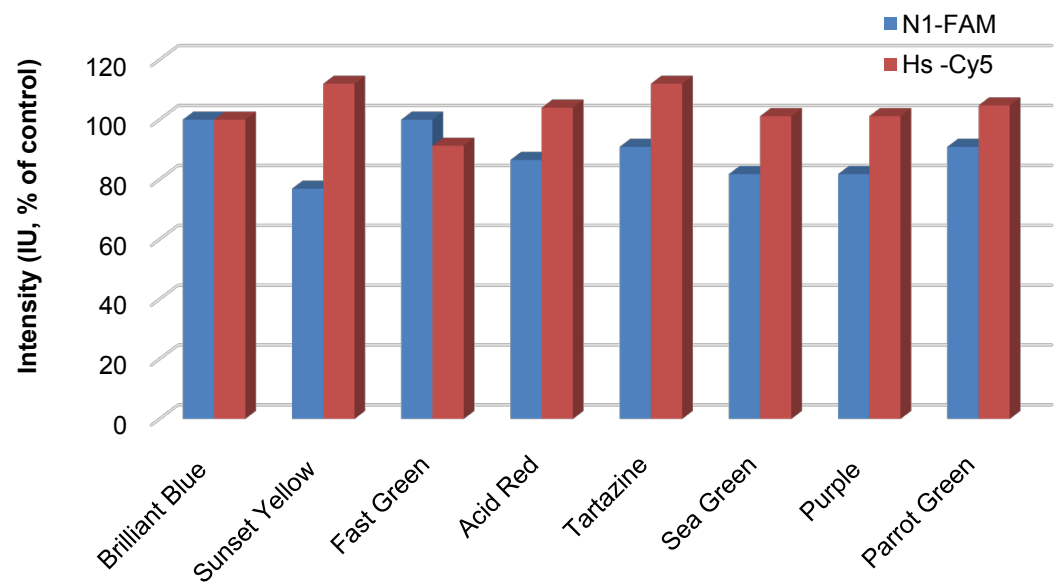

(b)

Figure 4. Comparative impact of Brilliant Blue, Acid Red 33, Fast Green, Sunset Yellow, Tartrazine, and derivative colorants on N1-FAM and Hs-Cy5 targets of SARS-CoC-2. (a) Ct values (b) Intensity (IU, \% of control).

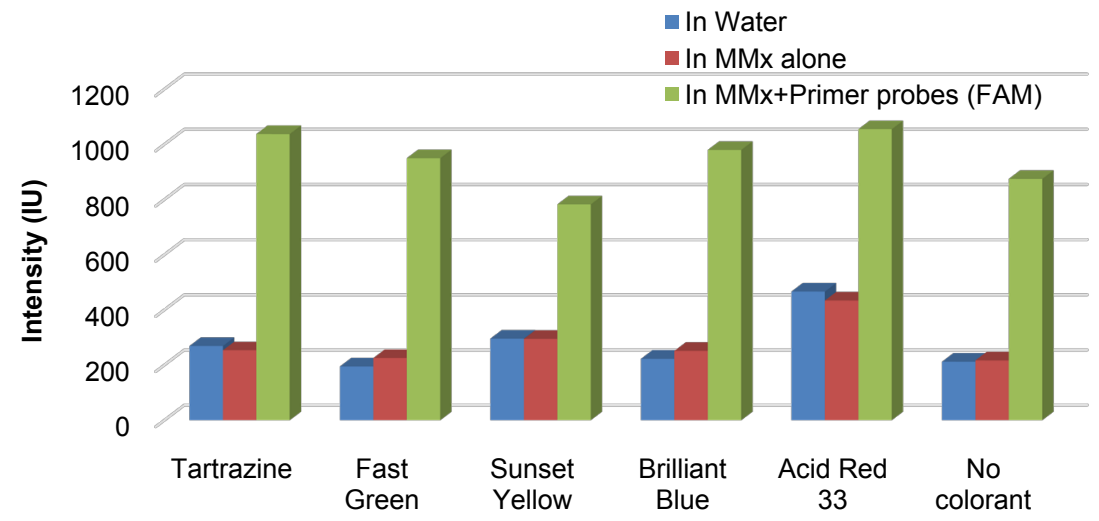

(a) 


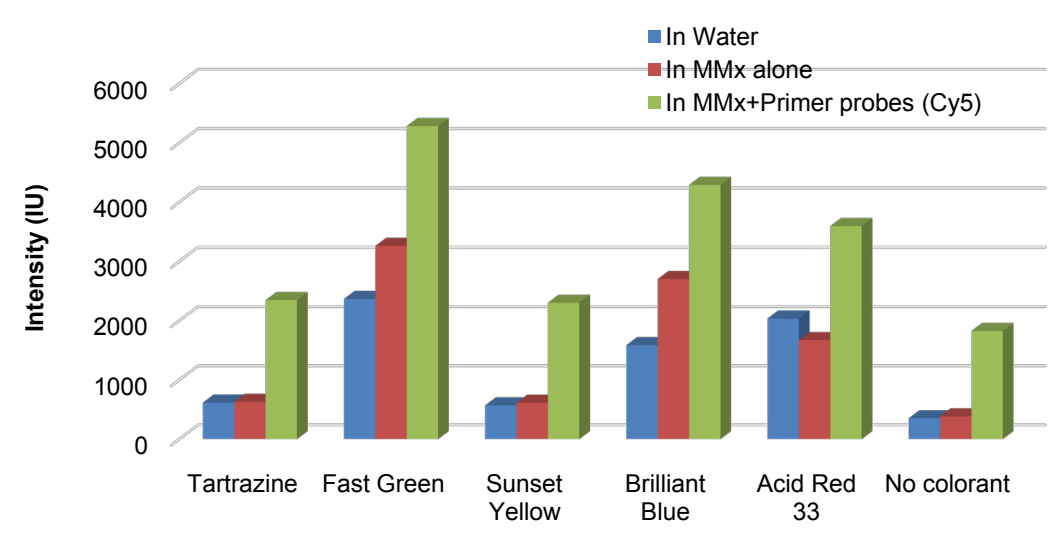

(b)

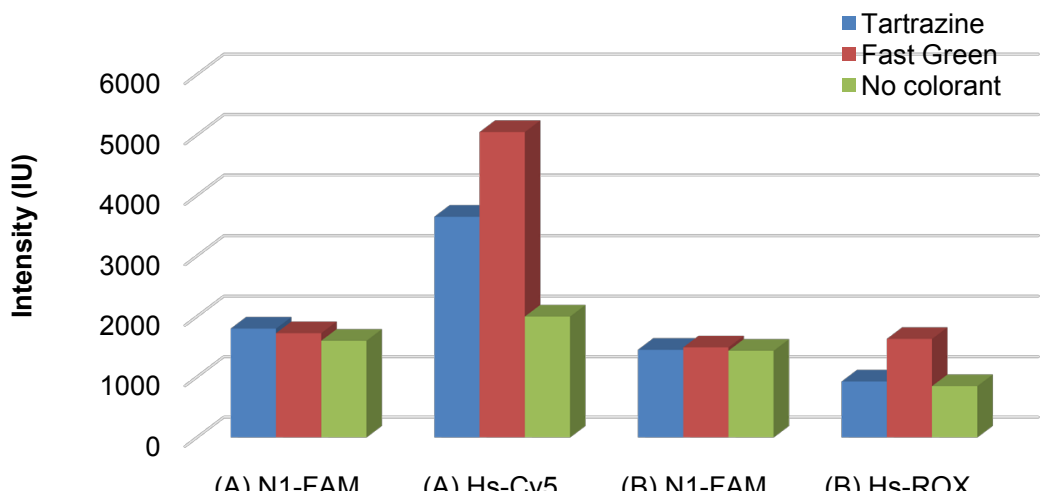
(A) N1-FAM
(A) Hs-Cy5
(B) N1-FAM
(B) Hs-ROX

(c)

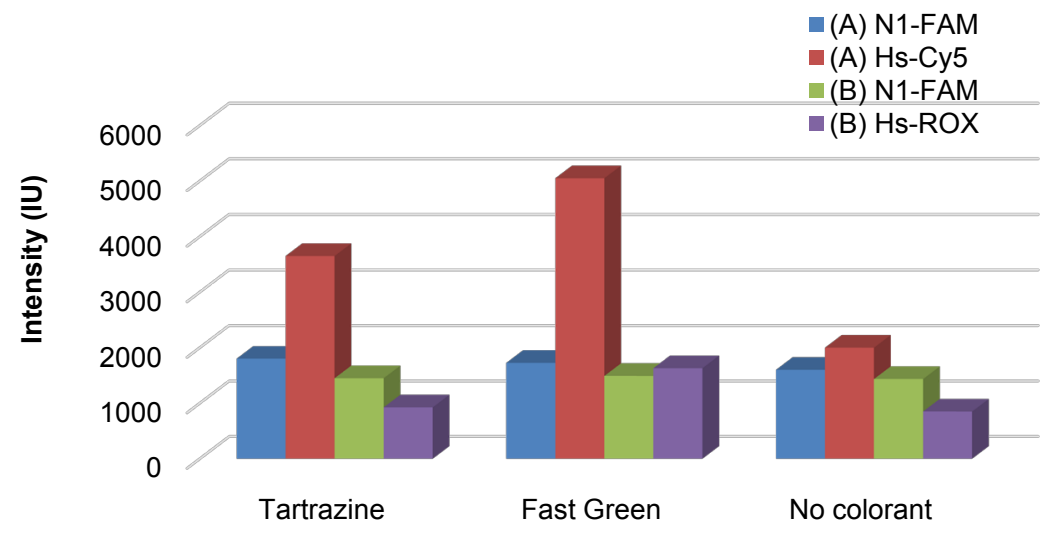

(d)

Figure 5. Background intensity of colorants running through thermocycling of 45 cycles in comparison to no-colorant control determined on channel-1 and 2 of AriaDNA ${ }^{\mathrm{TM}}$ Analyzer from the colorants tested as $1 \mu \mathrm{l}$ of each colorant in $10 \mu \mathrm{l}$ water, $1 \mu \mathrm{l}$ in $10 \mu \mathrm{l} \mathrm{Ul}$ traPlex $^{\mathrm{TM}} 1$-Step ToughMix ${ }^{\circledR}$, and $1 \mu \mathrm{l}$ of each colorant in $10 \mu \mathrm{l}$ of PCR mix containing ToughMix 1-step UltraPlex ${ }^{\mathrm{TM}}$ 1-Step ToughMix ${ }^{\circledR}$ of N1-FAM and Hs-Cy5. (a) Channel-1. (b) Channel-2. (c) Channel 2 with Hs-Cy5. (d) Channel-2 with Hs-ROX.

1-Step ToughMix ${ }^{\circledR}$, primers and probe, the background intensity ranged from 1.6 to $1.8,1.6$, and 1.3-fold of the no-colorant control. However, Fast Green, Brilliant Blue, and Acid Red 33 colorant ranged from 4.5 to 6.7, 4.3 to 8.5, and 2.4 to 2.9 -fold of the no-colorant control in water, in UltraPlex ${ }^{\mathrm{TM}} 1$-Step 
ToughMix $^{\circledR}$, and in the PCR mix containing UltraPlex ${ }^{\mathrm{TM}}$ 1-Step ToughMix ${ }^{\circledR}$, primers and probe, respectively (Figure $5(\mathrm{~b})$ ).

A comparison of the background intensities of two reporter dyes Hs-Cy5 and Hs-ROX on channel-2 of AriaDNA ${ }^{\mathrm{TM}}$ analyzer, were also compared for Tartrazine, Fast Green colorants, and no-colorant control. The fold difference of 3.9, 3.1 and 2.4 between Hs-Cy5 and Hs-ROX for Tartrazine, Fast Green and no-colorant control indicated that ROX has appreciably lower background than Cy5 (Figure 5(c), Figure 5(d)). The addition of $1 \mu \mathrm{l}$ of each test colorant in 10 $\mu$ of water or UltraPlex ${ }^{\text {TM }} 1$-Step ToughMix ${ }^{\circledR}$ or PCR mix containing UltraPlex ${ }^{\mathrm{TM}}$ 1-Step ToughMix ${ }^{\circledR}$ and primer probes of N1-FAM and Hs-Cy5 resulted in intensity units of -17 to $+14,-60$ to +90 , and -70 to +20 , respectively as the final background in the PCR assay (Figure 6(a), Figure 6(c)). This data indicates

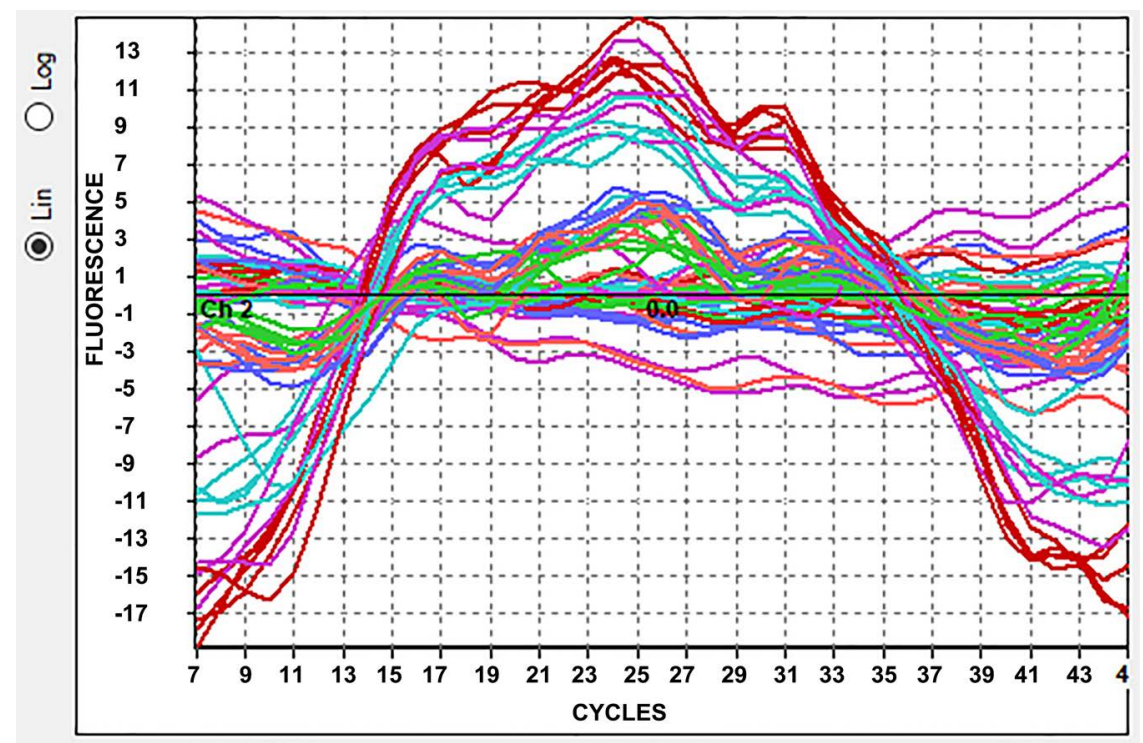

(a)

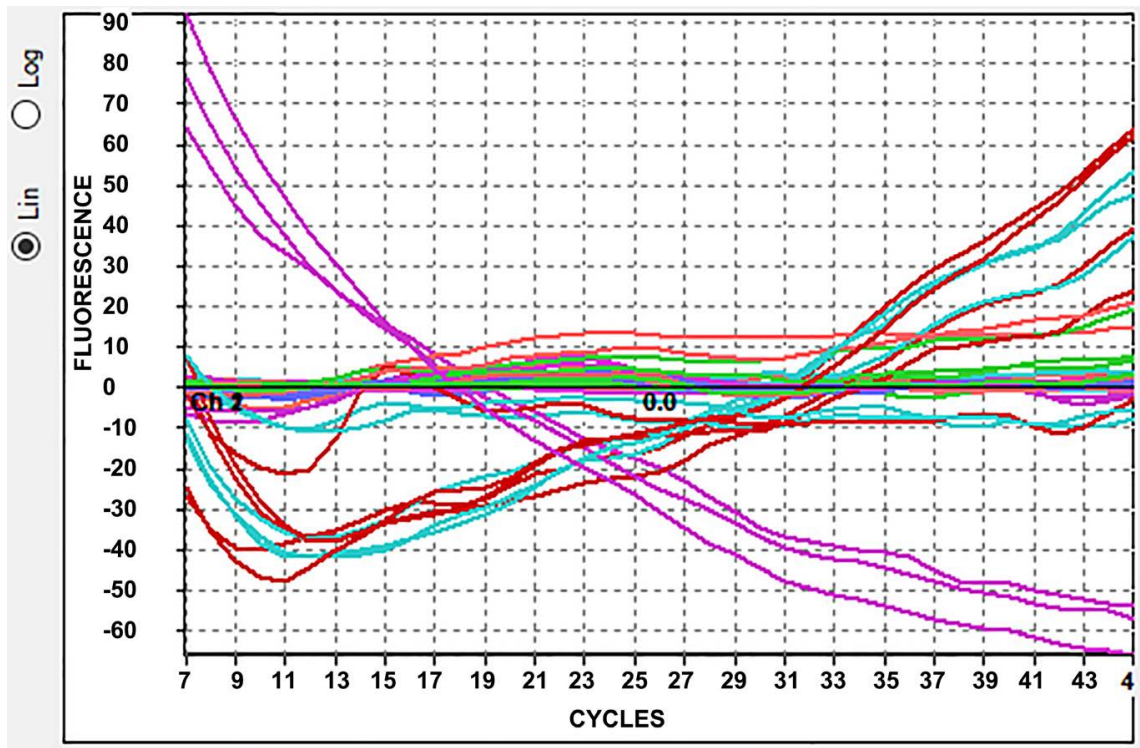

(b) 


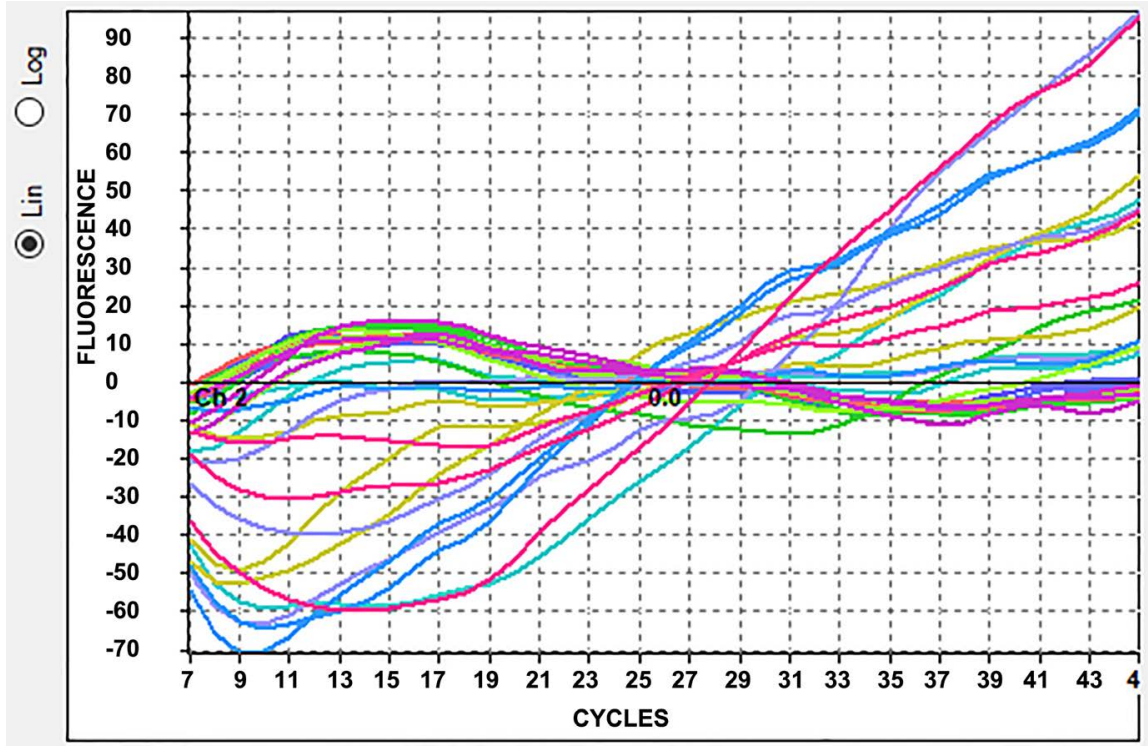

(c)

Figure 6. Background of the PCR run data applying "Exponential Background" option of the software indicating absence of background intensity towards channel-1 and 2 of AriaDNA ${ }^{\mathrm{TM}}$ Analyzer from all the test colorants added as sample (a). Tested $1 \mu \mathrm{l}$ of each colorant in $10 \mu \mathrm{l}$ water mix $(-17$ to +14$)$. (b) Tested $1 \mu \mathrm{l}$ in $10 \mu \mathrm{l} \mathrm{UltraPle{ } ^ { \mathrm { TM } }} 1$-Step ToughMix ${ }^{\circledR}(-60$ to +90$)$. (c) Tested $1 \mu$ l of each colorant in $10 \mu$ of PCR mix containing UltraPlex $^{\mathrm{TM}} 1$-Step ToughMix ${ }^{\circledR}$ and primer probes of N1-FAM and Hs-Cy5 $(-70$ to +20$)$.

the negligible contribution of the colorants in comparison to that of the PCR reaction mix. In realtime PCR analysis, the background intensities of the PCR mixes are subtracted by the software during analysis. Similarly, AriaDNA ${ }^{\mathrm{TM}}$ analyzer software also applies optional exponential background subtraction during analysis. Therefore, these background intensities do not interfere in the analysis.

Determining non-interference of colorants during PCR thermocycling: The PCR reporter dyes, and the colorants are known to have their specific absorbance and emission spectra that may interfere during the PCR run [18] [19]. Moreover, the data from screening food colorant formulations on compatibility with realtime PCR, and from the comparison of the intensity of the blank colorants, some food colorants formulations for food applications were not found to be compatible due to high optical absorbance [20]. Therefore, interference of the working solutions of these test colorants with channel- 1 and channel- 2 of AriaDNA ${ }^{\mathrm{TM}}$ analyzer was studied by running PCR with primer and probes of FAM, and Cy5 reporter dyes.

The absence of any signal from all the test colorants added as sample $(1 \mu \mathrm{l}$ in10 $\mu$ RT-PCR mix) in the 2-plex Microchip RT-PCR Covid-19 Detection kit preloaded with lyophilized FAM, and $\mathrm{Cy} 5$ reporter dyes, did not generate any signal indicating their inertness to the detection channels of the AriaDNA ${ }^{\mathrm{TM}}$ analyzer (Figure $6(\mathrm{c})$ ). This data also suggested the compatibility of these colorants in the microchip. Thus, these colorants can be used either for coloring of master mix for precision liquid handling in microchips or to color-coding of lyophilized kits in the microchip. 
Comparison of sensitivity and LOD of PCR w/o colorant: Effect of the working concentrations of all the 5 test colorants on sensitivity of the PCR at near technical LOD of the assay with spiked 1 copy/ $\mu$ l of N1-RNA and $1 \times 10^{4}$ copies/ $\mu \mathrm{l}$ of Hs-RNA was investigated in comparison to no-colorant in the assay at fast thermocycling. Comparable $\mathrm{Ct}$ values of N1-RNA at 1 copy/ $\mu \mathrm{l}$ in the presence of $1 \times 10^{4}$ copies/ $\mu$ l of Hs-RNA indicated that the sensitivity of the PCR assay does not get compromised at fast settings of thermocycling completing 45 PCR cycles in $32 \mathrm{~min}$ (Figures 7(a)-(d)).

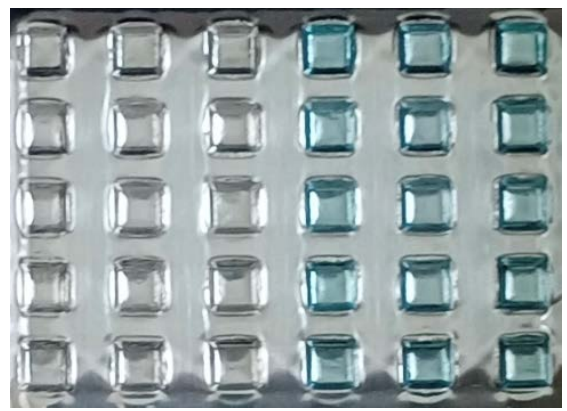

(a)

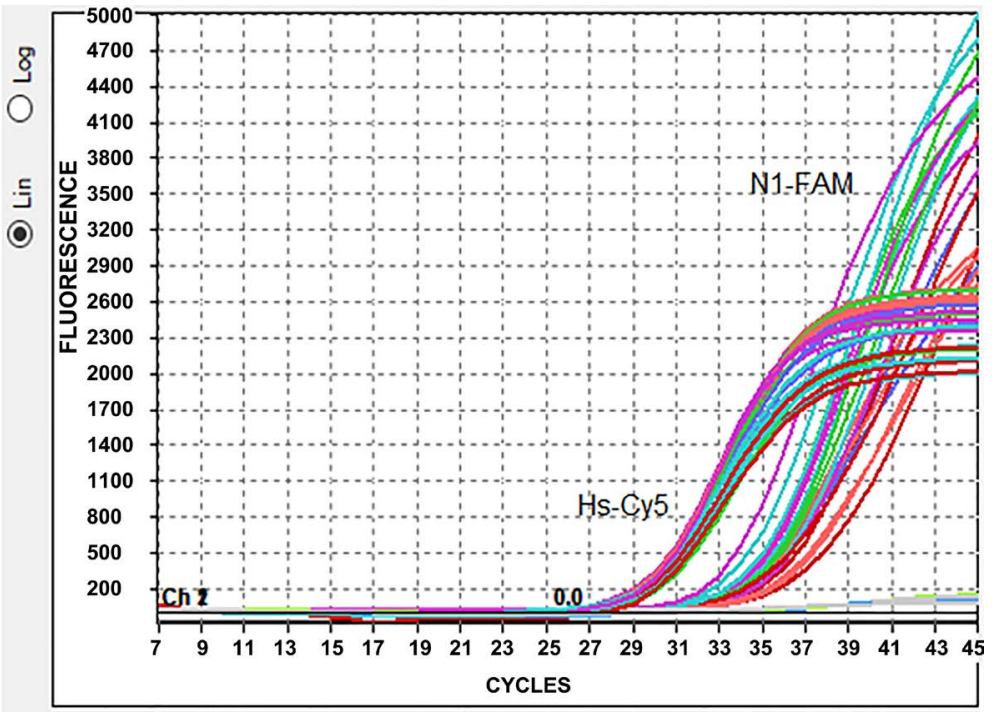

(b)

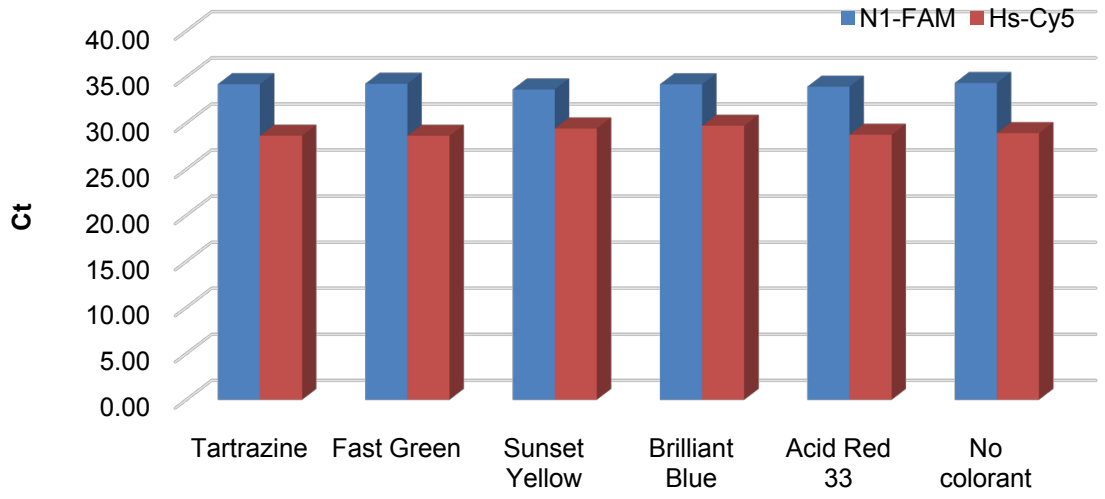

(c) 


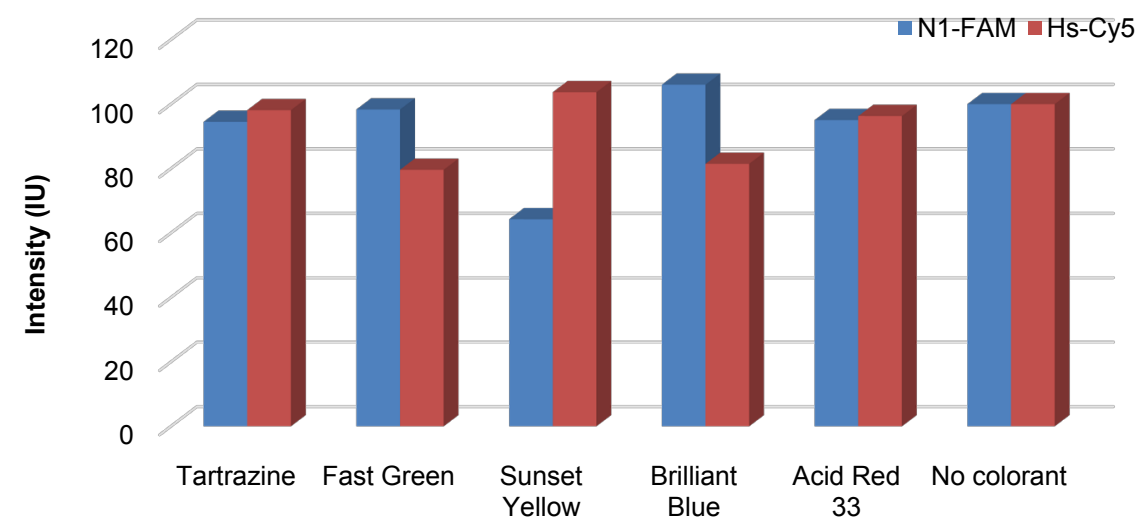

(d)

Figure 7. Effect on sensitivity of the PCR w/o colorants. (a) Image of 30-microwell format w/o Fast Green colorant (b) Sensitivity of N1-RNA at 1 copy/ $\mu$ in presence/absence of respective colorant and Hs-RNA $\left(1 \times 10^{4}\right.$ copies/ $\mu$ l) completing 45 cycles of PCR in 32 min with microchip containing lyophilized primers and probes of the N1-FAM and Hs-Cy5. (c) Comparative $\mathrm{Ct}$, (d) Comparative intensity as \% of no-colorant control intensity.

Additionally, the comparison of standard curves run with the standards ranging from $1 \mathrm{copy} / \mu \mathrm{l}$ to $1 \times 10^{4} \mathrm{copies} / \mu \mathrm{l}$ w/o the presence of Fast Green colorant displayed no influence of the colorant on qPCR performance (Figure $9(\mathrm{c})$ ). This data is supported by the VisiBlue ${ }^{\mathrm{TM}}$ colorant where the sensitivity of the PCR assay is not affected with presence of the VisiBlue ${ }^{\mathrm{TM}}$ colorant. The direct addition of VisiBlue ${ }^{\mathrm{TM}}$ to the Finnzymes DyNAmo qPCR mastermix for the amplification of $18 \mathrm{~S}$ rRNA is reported as having no significant difference in end fluorescence compared w/o the colorant.

Besides 30-microwell aluminum format, compatibility of Tartrazine, Acid Red 33, and Fast Green colorants lyophilized with primers and probes of the N1-FAM and Hs-ROX of SARS-CoV-2 in 48-microwell stainless-steel microchip was also investigated. Inertness of the colorants was displayed by amplification of both

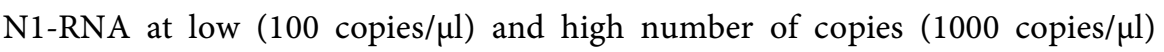
completing 45 cycles of PCR in 32 min comparable with no colorant control (Figures 8(a)-(f)). This data indicates equaling 30-microwell format, the higher density format of 48-microwell also did not affect the technical LOD of the spiked N1-RNA (Figure 9(a), Figure 9(b)).

Compatibility with different master mixes and stability of colorants: Compatibility of the presence of Fast Green colorant with 3 master mixes was reflected from the comparable $\mathrm{Ct}$ values and fluorescence intensity over 70-day duration on RT-PCR in 2-plex Microchip RT Covid-19 Detection Kit. No significant difference was observed in the performance of PCR in comparison to no-colorant control (Figure 10(a), Figure 10(b)). Additionally, the lyophilized form of the Lyo NZYSupreme One-step RT-qPCR Probe and Lyo NZYSpeedy one-step RT-qPCR Probe master mix offers an edge over the liquid form QuantaBio's UltraPlex ${ }^{\mathrm{TM}} 1$-Step ToughMix ${ }^{\circledR}$ for the ease of the cold-chain free shipment. 


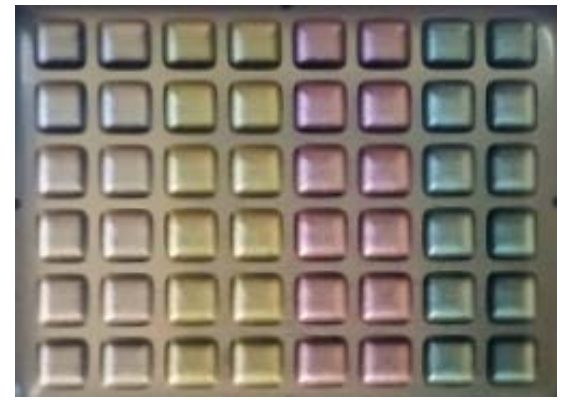

(a)

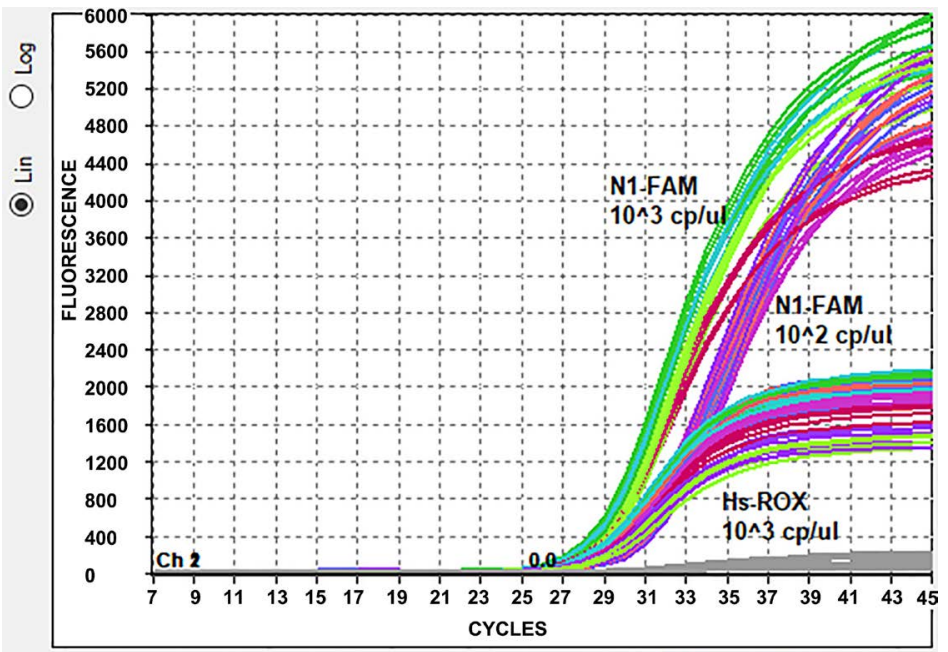

(b)

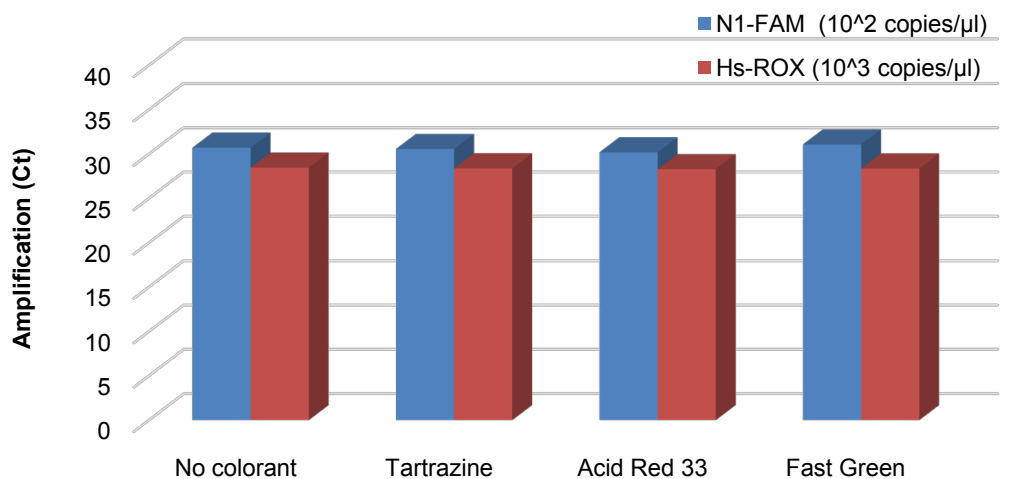

(c)

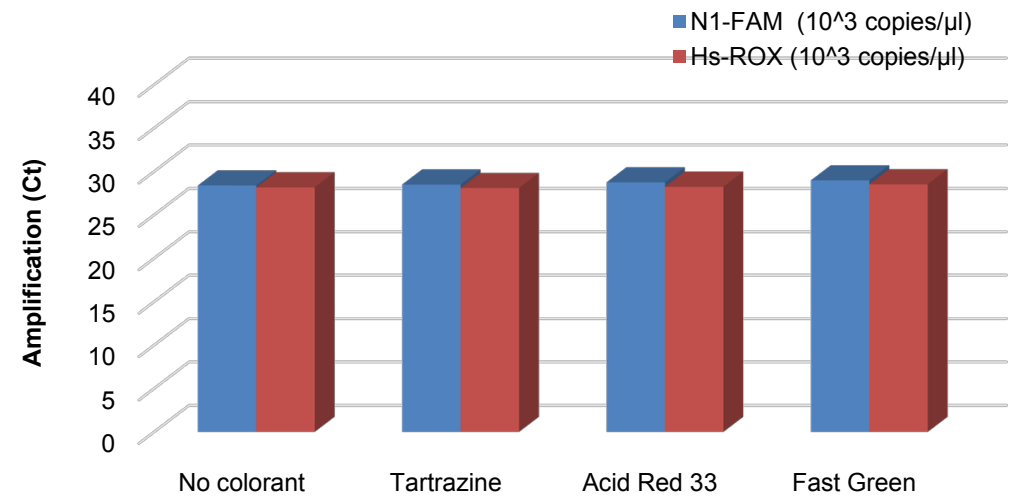

(d) 


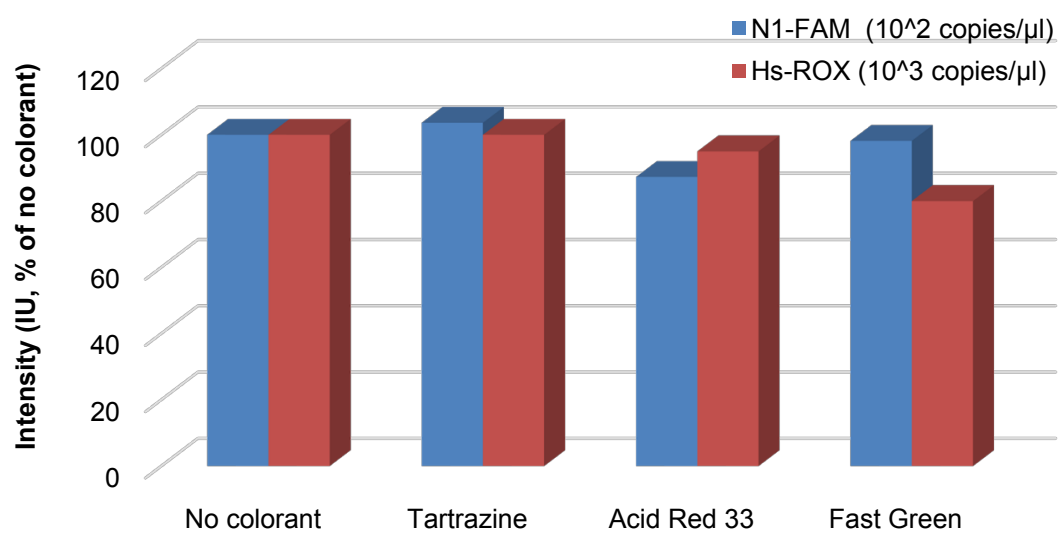

(e)

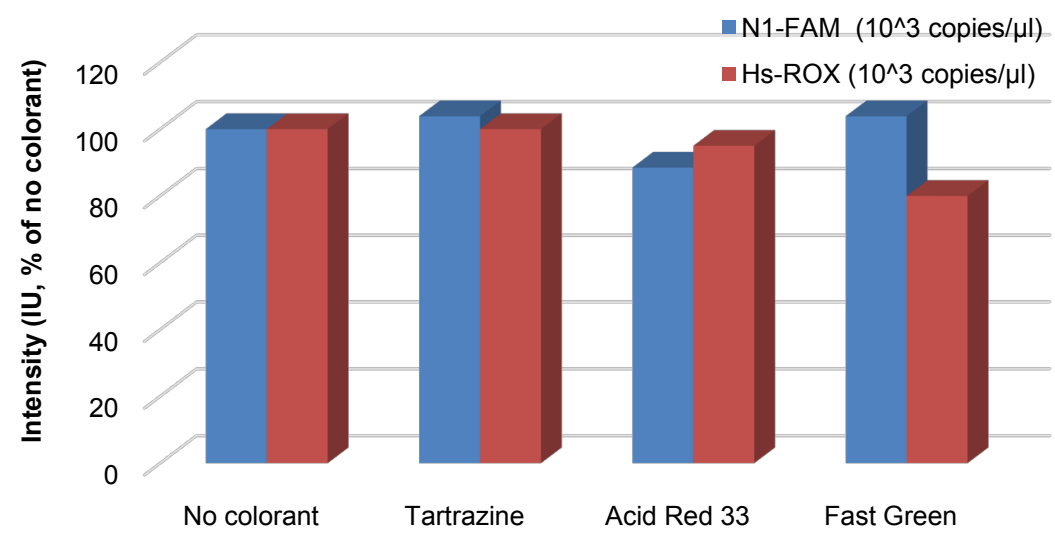

(f)

Figure 8. Compatibility of lyophilized colorants along with primers and probes of the N1-FAM and Hs-ROX of SARS-CoV-2 in 48 microwell stainless-steel microchip. (a) Visibility of Tartrazine, Acid Red 33, and Fast Green colorants in the microchip. (b) Inertness of the colorants on amplification Ct of both N1-RNA at low (100 copies/ $\mu$ l) and high (1000 copies/ $\mu$ l) completing 45 cycles of PCR in 32 min with microchip containing lyophilized primers and probes. (c) Comparative Ct with 100 copies/ $\mu$ l. (d) Comparative Ct with 1000 copies/ $\mu$ l. (e) Comparative intensity as \% of no-colorant control intensity with 100 copies/ $\mu$ l. (f) Comparative intensity as \% of no-colorant control intensity with 1000 copies/ $\mu$ l.

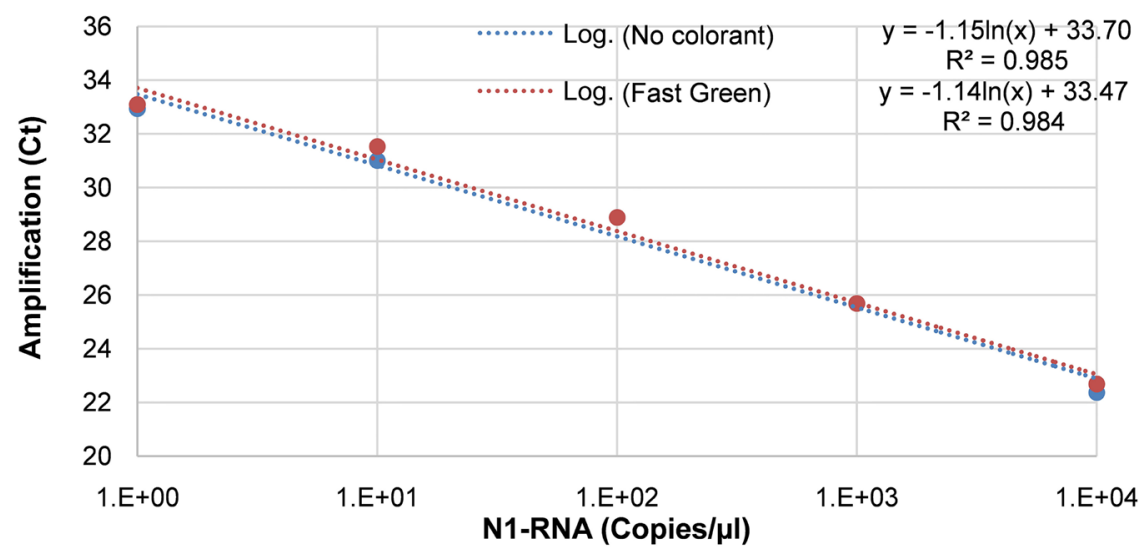

(a) 


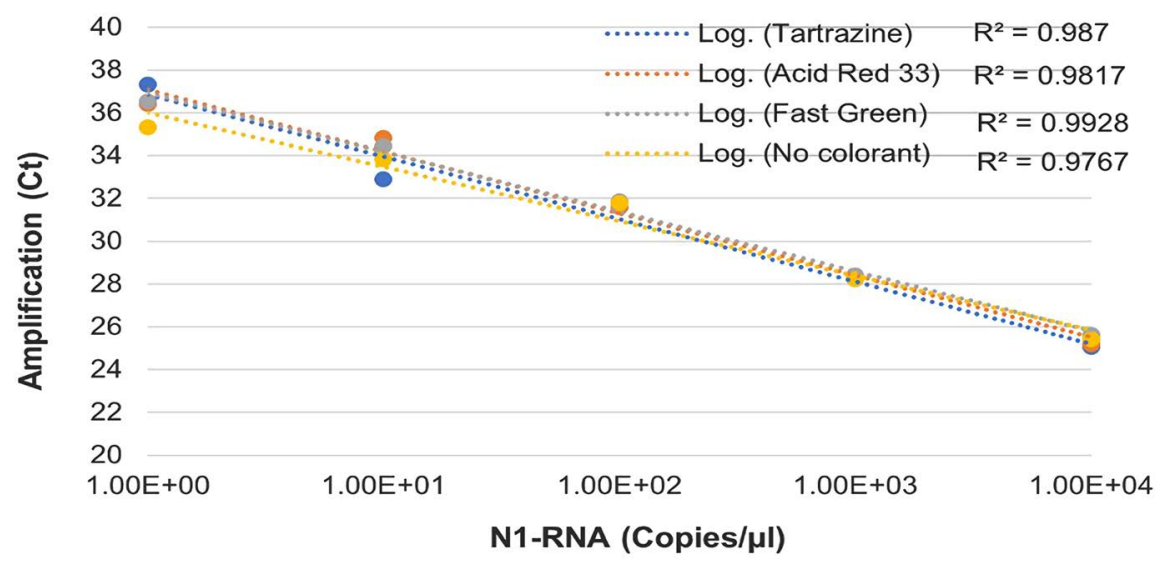

(b)

Figure 9. Standard curves of N1-RNA displaying effect on sensitivity and LOD of PCR w/o colorants (a) 30-microwell format w/o Fast Green colorant. (b) 48-microwell format w/o Tartrazine, Acid Red 33, and Fast Green colorants.

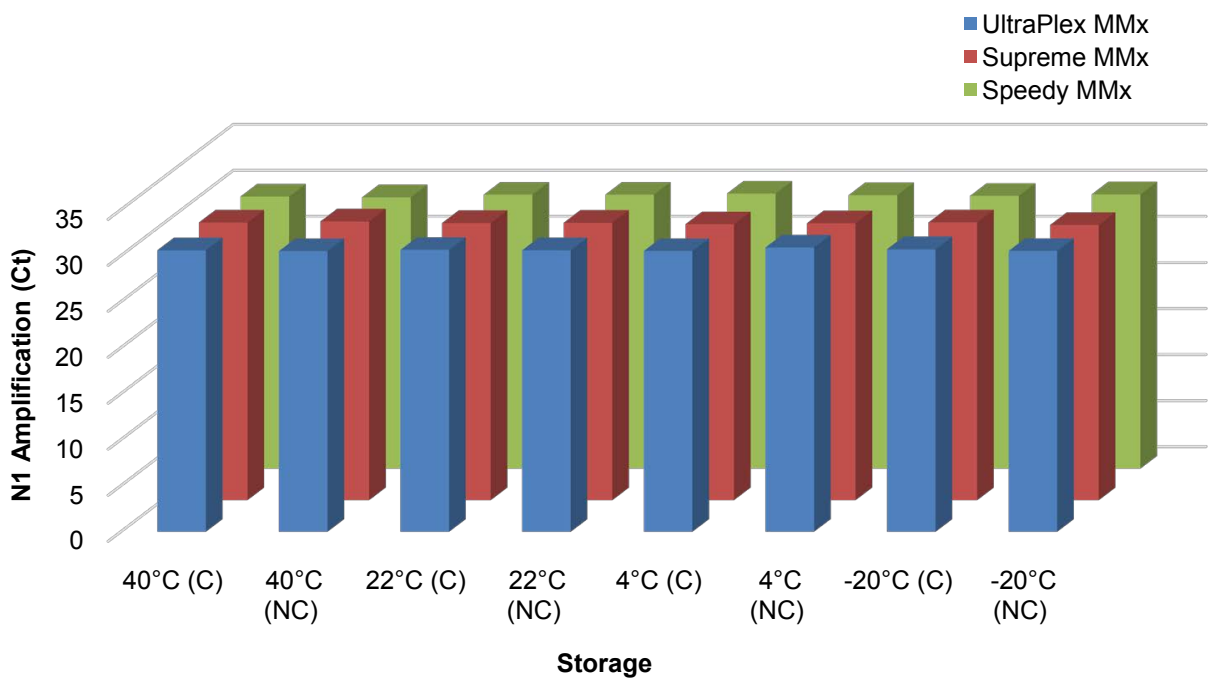

(a)

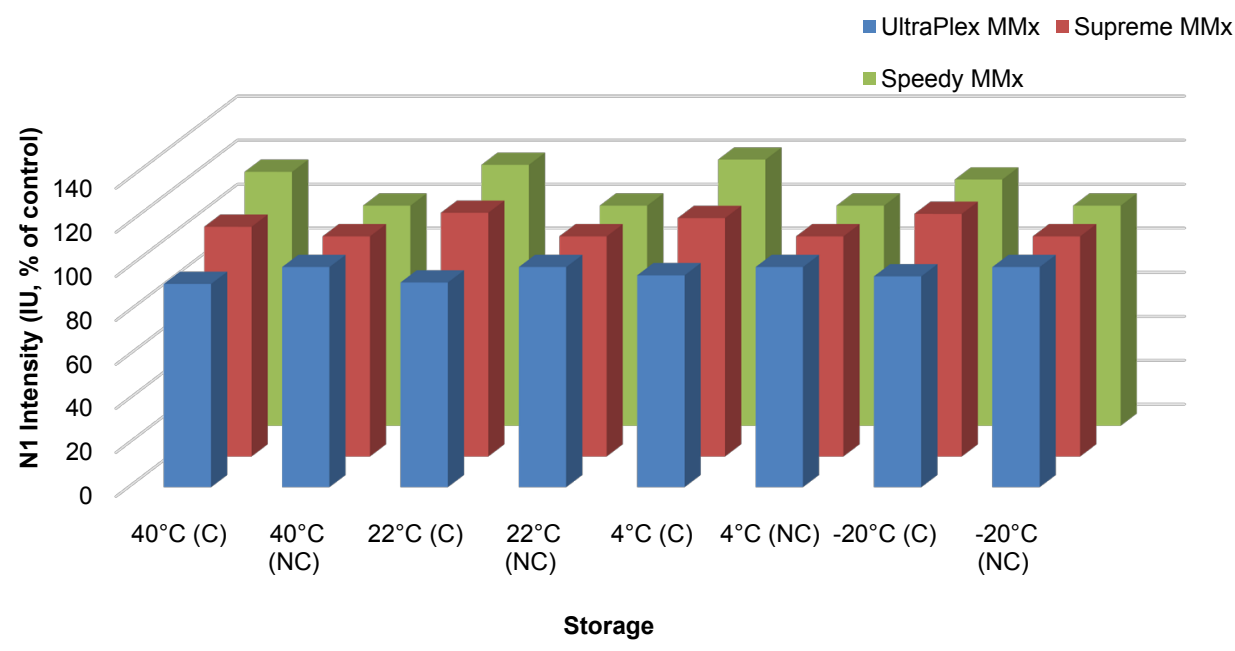

(b) 


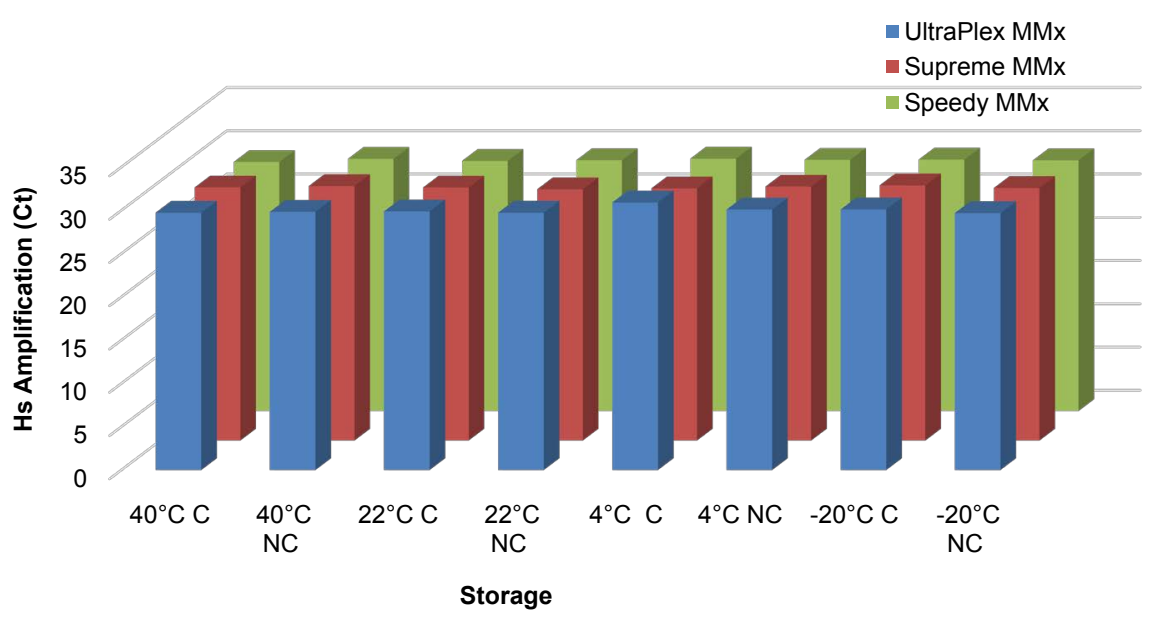

(c)

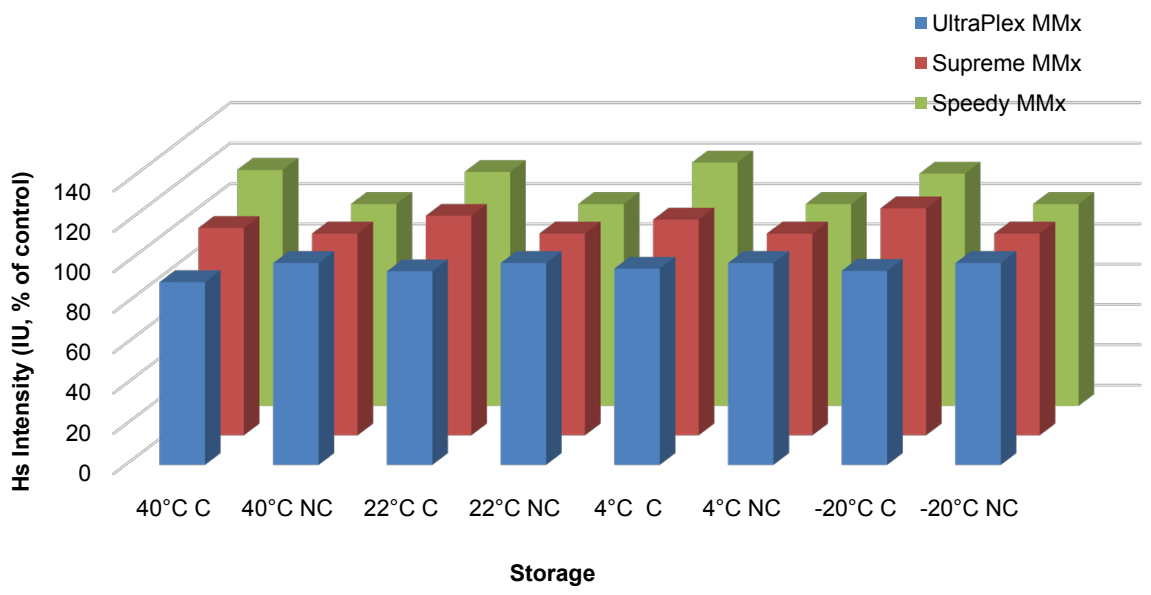

(d)

Figure 10. Compatibility and stability of the microchips lyophilized pellet of w/o Fast Green colorant, primers and probes of N1-FAM and Hs-Cy5 stored at $40^{\circ} \mathrm{C}, 22^{\circ} \mathrm{C}, 4^{\circ} \mathrm{C}$, and $-20^{\circ} \mathrm{C}$ and further tested with QuantaBio's UltraPlex ${ }^{\mathrm{TM}}$ 1-Step ToughMix ${ }^{\circledR}$, Lyo NZYSupreme One-step RT-qPCR Probe Mix, and Lyo NZYSpeedy One-step RT-qPCR Probe Master in lyophilized 2-plex Microchip RT-PCR Covid-19 kit. And stability: (a) Amplification Ct of N1-FAM. (b) Amplification Ct of Hs-Cy5. (c) Amplification intensity of N1-FAM as \% of no-colorant control. (d) Amplification intensity of Hs-Cy5 as \% of no-colorant control.

During these stability studies, the Ct values and fluorescence intensity did not significantly differ in comparison of w/o colorant (Figure 10(c), Figure 10(d)). The storage at low and high temperatures over 70 days also did not affect the visibility of the colorant in the microchip upon reconstitution of the lyophilized reagent pellet in the microchip during RT-PCR set up. Similarly, in the previously conducted studies, the presence or absence of food colorant formulation of blue, green, red, yellow, and violet colorants for both PoAc-FAM (channel-1) and IC-ROX (channel-2) of AriaDNA ${ }^{\mathrm{TM}}$ in the lyophilized microchip did not indicate any significant impact on activity of the PCR reagents [20]. These observations suggest that the tested colorants can be successfully used to add us- 
er-friendliness of the ready-to-use lyophilized microchips.

Test of colorant-loaded microchips with clinical samples: The PEC clinical sample were tested for both intra-and inter-microchip comparison where microchip 1 contained 2-plex formats of N1-FAM/Hs-Cy5 primer-probes, and microchip 2 with N1-FAM/Hs-ROX primer-probes. Tartrazine colorant with 0.4 $\mathrm{Ct}$ lower and Fast Green with no difference of $\mathrm{Ct}$ than the no-colorant control indicated insignificant impact on Ct values of N1-FAM in both intra- and inter microchips.

Similarly, the intensity of N1-FAM target was also insignificantly affected by the Tartrazine colorant displaying 6\% and Fast Green colorant $8 \%$ lower intensity than no-colorant control (Figure 11(a), Figure 11(b). Four certified negative samples tested in N1-FAM/Hs-Cy5 lyophilized microchips emerged negative displaying no impact of colorant on their detection for N1-FAM target while Hs-Cy5 reported positive from human DNA present in all the positive and negative samples (Figure 11(a), Figure 11(b)). The four positive samples run in N1-FAM/HS-ROX lyophilized microchip displayed -0.4 to $+0.3 \mathrm{Ct}$ difference

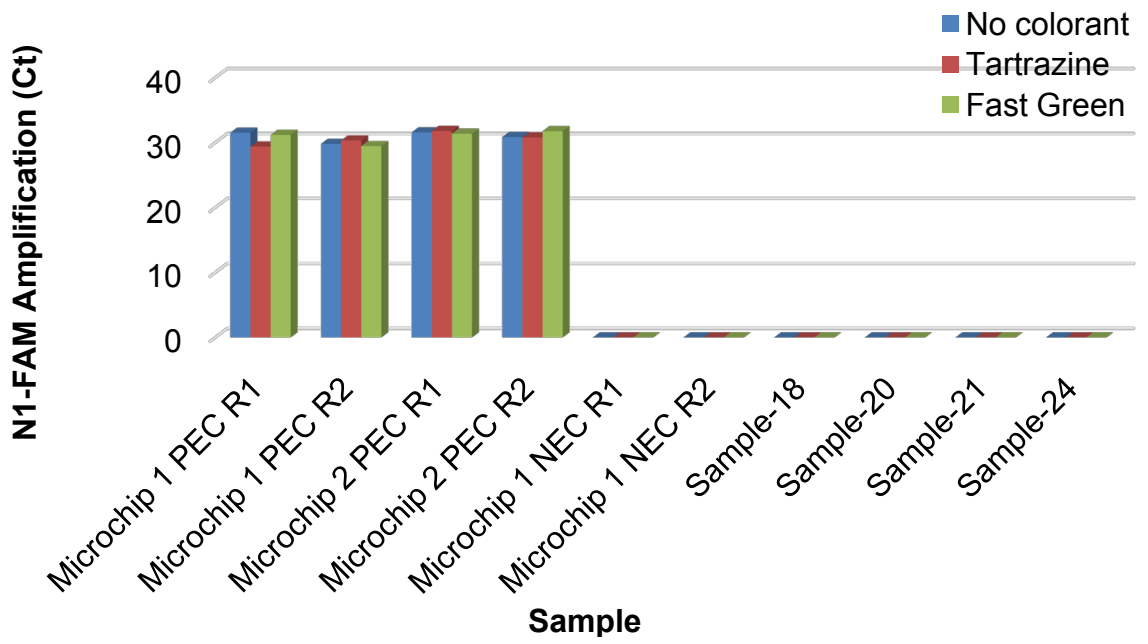

(a)

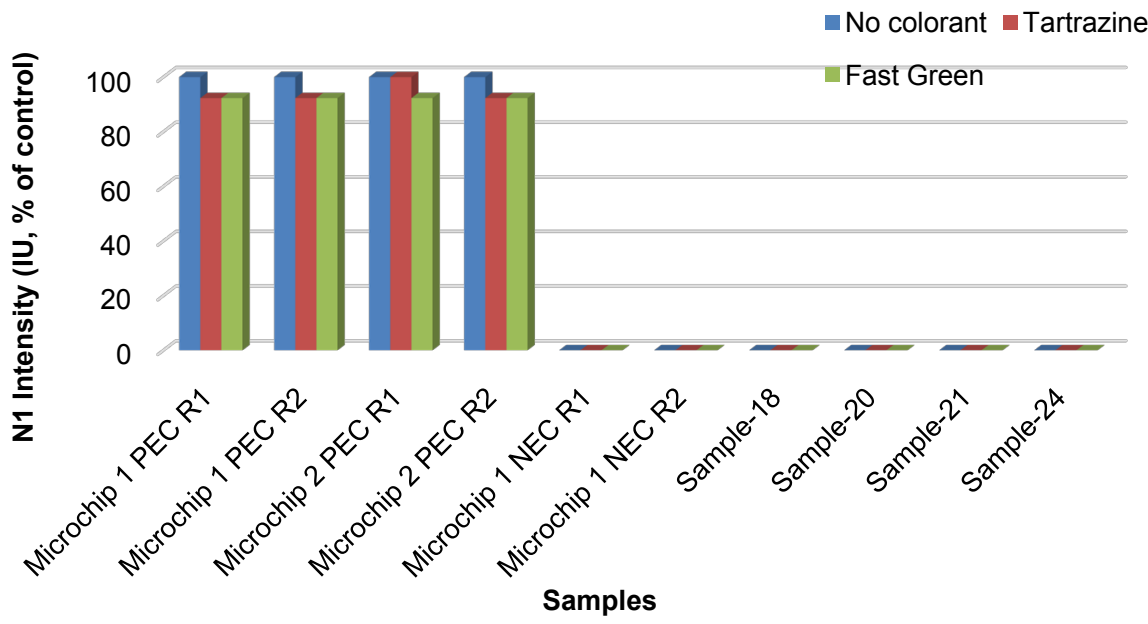

(b) 


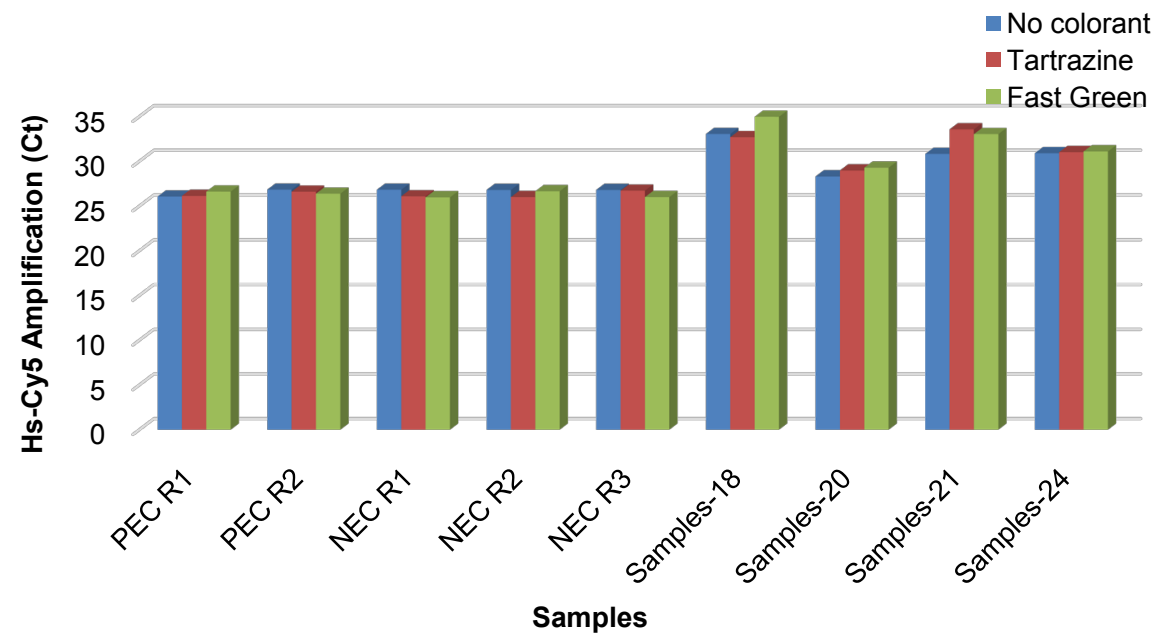

(c)

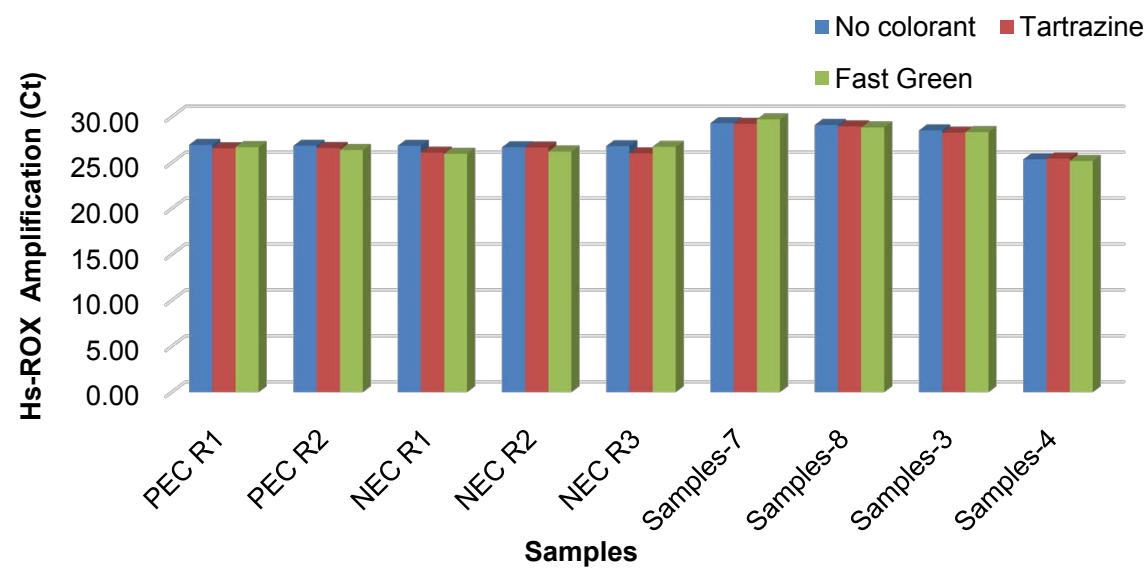

(d)

Figure 11. Inter- and intra-microchip impact of colorants with testing of clinical samples. (a-b) Impact on Ct of N1-target amplification fluorescence intensity (IU as \% of no-colorant control) from PEC and NEC sample run as duplicate in the microchip-1 (N1-FAM/Hs-Cy5), and microchip-2 (N1-FAM/Hs-ROX). (c-d) Impact on Ct of Hs-Cy5 versus Hs-ROX target amplified from human genome in samples.

for Tartrazine and Fast Green colorants from that of no-colorant control (Figure 11(d)). Similarly, the Hs-ROX target reported from the human genome in saliva of all the patient samples, the Ct values of each sample did not significantly differ among the microwells containing lyophilized reagents where both Tartrazine and Fast Green colorants had $<0.3 \mathrm{Ct}$ difference from that of the no-colorant control (Figure 11(c), Figure 11(d)).

Acceptable rank order of colorants: Applying acceptability criteria on these colorants, a rank order of the colorants is presented in Table 4 that suggests the applicability of these colorants with insignificant compromise on confidence of the PCR detection of SARS-CoV-2. The colorants or the derivative colorants created from mixing different colorants can generate other color shades for expanding multi color-coding of the kits. 
Table 4. Acceptability rank order of the colorants.

\begin{tabular}{|c|c|c|c|c|c|c|c|c|c|c|c|c|c|}
\hline \multirow{3}{*}{ Colorants } & \multicolumn{4}{|c|}{ Background intensity of $1 \mu \mathrm{l}$ colorant } & \multirow{3}{*}{ 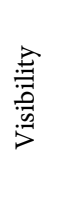 } & \multirow{3}{*}{ 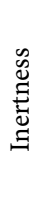 } & \multirow{3}{*}{$\begin{array}{l}\text { 品 } \\
\text { क्ञ } \\
\dot{D}\end{array}$} & \multicolumn{4}{|c|}{$\begin{array}{c}\text { N1-RNA } 1 \text { copy/ } \mu \mathrm{l} \\
\text { Hs-RNA } 10^{4} \text { copies } / \mu \mathrm{l}\end{array}$} & \multicolumn{2}{|c|}{ Covid-19 patient samples } \\
\hline & \multirow{2}{*}{\multicolumn{2}{|c|}{ In Water In MMx - }} & \multicolumn{2}{|c|}{ In PCR mix } & & & & \multicolumn{2}{|c|}{$\mathrm{Ct}$} & \multicolumn{2}{|c|}{$\mathrm{IU}$} & \multirow{2}{*}{$\frac{\mathrm{Ct}}{\mathrm{N} 1-\mathrm{FAM}}$} & \multirow{2}{*}{$\frac{\mathrm{IU}}{\mathrm{Hs}-\mathrm{ROX}}$} \\
\hline & & & N1-FAM & Hs-Cy5 & & & & N1-FAM & Hs-Cy5 & N1-FAM & Hs-Cy5 & & \\
\hline Tartrazine & 1 & 1 & 2 & 1 & 1 & 1 & 1 & 1 & 1 & 1 & 1 & 1 & 1 \\
\hline Fast Green & 1 & 1 & 1 & 2 & 1 & 1 & 1 & 1 & 1 & 1 & 1 & 1 & 1 \\
\hline Sunset Yellow & 1 & 1 & 2 & 1 & 1 & 1 & ND & 1 & 1 & 1 & 1 & ND & ND \\
\hline Brilliant Blue & 1 & 1 & 1 & 2 & 1 & 1 & 1 & 1 & 1 & 1 & 1 & ND & ND \\
\hline Acid Red 33 & 2 & 2 & 2 & 2 & 1 & 1 & ND & 1 & 1 & 1 & 1 & ND & ND \\
\hline No colorant & $\mathrm{R}$ & $\mathrm{R}$ & $\mathrm{R}$ & $\mathrm{R}$ & $\mathrm{R}$ & $\mathrm{R}$ & $\mathrm{R}$ & $\mathrm{R}$ & $\mathrm{R}$ & $\mathrm{R}$ & $\mathrm{R}$ & $\mathrm{R}$ & $\mathrm{R}$ \\
\hline
\end{tabular}

$\mathrm{ND}=$ Not determined, $\mathrm{R}=$ Reference.

\section{Conclusion}

The results obtained in the present studies suggest that the tested colorants can be successfully used to add user-friendliness of the ready-to-use lyophilized microchips to improve liquid handling. The storage at low and high temperatures confirmed that visibility of the colorant in the microchip is not affected for at least 70 days.

\section{Acknowledgements}

The support extended by Dr. Natallia Varankovich, and Er. Steven Hao in manufacturing of microchips is acknowledged.

\section{Conflicts of Interest}

The authors declare no conflicts of interest regarding the publication of this paper.

\section{References}

[1] Razvan, C., Yaseen, I., Unrau, P.J., Lowe, C.F., Ritchie, G., Romney, M.G., Sin, D.D., Gill, S. and Slyadnev, M. (2012) Microchip RT-PCR Detection of Nasopharyngeal SARS-CoV-2 Samples. Journal of Molecular Diagnostics, 8, S1525-S1578.

[2] Gill, R., Gill, S., Slyadnev, M. and Stroganov, A. (2018) Identification and Quantitation of Cashmere (Pashmina) Fiber and Wool Using Novel Microchip Based Real-Time PCR Technology. Journal of Textile Science and Technology, 4, 141-150. https://doi.org/10.4236/jtst.2018.44010

[3] Nikitin, M.M., Statsyuk, N.V., Frantsuzov, P.A., Dzhavakhiya, V.G. and Golikov, A.G. (2018) Matrix Approach to the Simultaneous Detection of Multiple Potato Pathogens by Real-Time PCR. Journal of Applied Microbiology, 124, 797-809. https://doi.org/10.1111/jam.13686

[4] Nikitin, M.M., Statsyuk, N.V., Frantsuzov, P.A., Pridannikov, M.V. and Golikov, A.G. (2017) Rapid and Simple Detection of Two Potato Cyst Nematode Species by Real-Time Multiplex PCR Using Preserved Microarray-Based Test Systems. Russian 
Journal of Nematology, 25, 51-60.

http://www.russjnematology.com/Articles/rjn251/Nikitin_RJN2017_1_FIN2.pdf

[5] Bogdanov, K.V., Nikulina, T.S., Lomaia, E.G., Slyadnev, M.N. and Zaritskey, A.Y. (2017) Identification of Oncogene Mutations in Leukemia Patients Using Microchip-Based PCR Analysis. Russian Journal of Bioorganic Chemistry, 43, 544-551. https://doi.org/10.1134/S1068162017040033

[6] Abdulina, D.R., Iutynska, G.O., Anjskina, A.I. and Nikitin, M.M. (2020) Detection of Sulfate-Reducing Bacteria from Various Ecotopes by Real-Time PCR. Biotechnologia Acta, 13, 38-47. https://doi.org/10.15407/biotech13.02.038

[7] Tong, R., Zhang, L., Song, Q., Hu, C., Chen, X., Lou, K., Gong, X., Gao, Y. and Wen, W. (2019) A Fully Portable Microchip Real-Time Polymerase Chain Reaction for Rapid Detection of Pathogen. Electrophoresis, 40, 1699-1707.

https://doi.org/10.1002/elps.201900090

[8] Babiker, A., Myers, C.W., Hill, C.E. and Guarner, J. (2020) SARS-CoV-2 Testing. American Journal of Clinical Pathology, 153, 706-708. https://doi.org/10.1093/ajcp/aqaa052

[9] Zhou, P., Yang, X.-L., Wang, X.-G., Hu, B., Zhang, L., Zhang, W., Si, H.-R., Zhu, Y., Li, B., Huang, C.-L., Chen, H.-D., Chen, J., Luo, Y., Guo, H., Jiang, R.-D., Liu, M.-Q., Chen, Y., She, X.-R., Wang, X., Zheng, X.-S., Zhao, K., Chen, Q.-J., Deng, F., Liu, L.-L., Yan, B., Zhan, F.-X., Wang, Y.-Y., Xiao, G.-F. and Shi, Z.-L. (2020) A Pneumonia Outbreak Associated with a New Coronavirus of Probable Bat Origin. Nature, 579, 270-273. https://doi.org/10.1038/s41586-020-2012-7

[10] Zhang, Y., Odiwuor, N., Xiong, J., Sun, L., Nyaruaba, R.O., Wei, H. and Tanner, N.A. (2020) Rapid Molecular Detection of SARS-CoV-2 (COVID-19) Virus RNA Using Colorimetric LAMP. https://doi.org/10.1101/2020.02.26.20028373

[11] Lamb, L.E., Bartolone, S.N., Ward, E. and Chancellor, M.B. (2020) Rapid Detection of Novel Coronavirus (COVID-19) by Reverse Transcription-Loop-Mediated Isothermal Amplification. https://doi.org/10.1101/2020.02.19.20025155

[12] El-Tholoth, M., Bau, H.H. and Song, J. (2020) A Single and Two-Stage, ClosedTube, Molecular Test for the 2019 Novel Coronavirus (COVID-19) at Home, Clinic, and Points of Entry. https://doi.org/10.26434/chemrxiv.11860137.v1

[13] Yu, L., Wu, S., Hao, X., Dong, X., Mao, L., Pelechano, V., Chen, W.H. and Yin, H. (2020) Rapid Detection of COVID-19 Coronavirus Using a Reverse Transcriptional Loop-Mediated Isothermal Amplification (RT-LAMP) Diagnostic Platform. Clinical Chemistry, 66, 975-977. https://doi.org/10.1093/clinchem/hvaa102

[14] Rabe, B.A. and Cepko, C. (2020) SARS-CoV-2 Detection Using an Isothermal Amplification Reaction and a Rapid, Inexpensive Protocol for Sample Inactivation and Purification. https://doi.org/10.1101/2020.04.23.20076877

[15] Bustin, S.A. and Nolan, T. (202) RT-qPCR Testing of SARS-CoV-2: A Primer. International Journal of Molecular Sciences, 21, 3004. https://doi.org/10.3390/ijms21083004

[16] Udugama, B., Kadhiresan, P., Kozlowski, H.N., Malekjahani, A., Osborne, M., Li, V.Y.C., Chen, H. and Mubareka, S. (2020) Diagnosing COVID-19: The Disease and Tools for Detection. ACS Nano, 14, 3822-3835.

https://doi.org/10.1021/acsnano.0c02624

[17] European Centre for Disease Prevention and Control, Stockholm (2020) An Overview of the Rapid Test Situation for COVID-19 Diagnosis in the EU/EEA.

https://www.ecdc.europa.eu/sites/default/files/documents/Overview-rapid-test-situa tion-for-COVID-19-diagnosis-EU-EEA.pdf 
[18] Jaggi, N., Yadav, K. and Giri, M.K. (2014) Static Studies of Absorption and Emission Spectra of Acid Yellow 17-An Azo Dye. Journal of Pure and Applied Physics, 52, 742-746.

http://nopr.niscair.res.in/bitstream/123456789/29597/1/IJPAP\%2052\%2811\%29\%20 742-746.pdf

[19] Ntrallou, K., Gika, H. and Tsochatzis, E. (2020) Analytical and Sample Preparation Techniques for the Determination of Food Colorants in Food Matrices. Foods, 9, 58. https://doi.org/10.3390/foods9010058

[20] Gill, S., Slyadnev, M. and Stroganov, A. (2017) Lumex Instruments Canada. Laboratory Focus May/June 2017.

https://laboratoryfocus.ca/validation-of-colorants-for-colour-coding-of-lyophilizedreagents-in-microchips-for-real-time-pcr-ariadna 